\title{
Identification and Characterization of a Novel Integrin-Linked Kinase Inhibitor
}

\author{
Su-Lin Lee ${ }^{1}$, En-Chi Hsu ${ }^{1}$, Chih-Chien Chou ${ }^{1}$, Hsiao-Ching Chuang ${ }^{1}$, Li-Yuan Bai ${ }^{2}$, Samuel \\ K. Kulp ${ }^{1}$, and Ching-Shih Chen ${ }^{1,{ }^{*}}$ \\ ${ }^{1}$ Division of Medicinal Chemistry, College of Pharmacy and Comprehensive Cancer Center, The \\ Ohio State University, Columbus, Ohio \\ 2Division of Hematology and Oncology, Department of Internal Medicine, China Medical \\ University, Taichung, Taiwan
}

\begin{abstract}
Integrin-linked kinase (ILK) represents a relevant target for cancer therapy in light of its role in promoting oncogenesis and tumor progression. Through the screening of an in-house focused compound library, we identified $N$-Methyl-3-(1-(4-(piperazin-1-yl)phenyl)-5-(4'-(trifluoromethyl)[1,1'-biphenyl]-4-yl)-1H-pyrazol-3-yl)propanamide (22) as a novel ILK inhibitor $\left(\mathrm{IC}_{50}, 0.6 \mu \mathrm{M}\right)$, which exhibited high in vitro potency against a panel of prostate and breast cancer cell lines $\left(\mathrm{IC}_{50}\right.$, $1-2.5 \mu \mathrm{M}$ ), while normal epithelial cells were unaffected. Compound 22 facilitated the dephosphorylation of Akt at Ser-473 and other ILK targets, including glycogen synthase kinase-3 $\beta$ and myosin light chain. Moreover, 22 suppressed the expression of the transcription/translation factor YB-1 and its targets HER2 and EGFR in PC-3 cells, which could be rescued by the stable expression of constitutively active ILK. Evidence indicates that $\mathbf{2 2}$ induced autophagy and apoptosis, both of which were integral to its antiproliferative activity. Together, this broad spectrum of mechanisms underlies the therapeutic potential of $\mathbf{2 2}$ in cancer treatment, which is manifested by its in vivo efficacy as a single oral agent in suppressing PC-3 xenograft tumor growth.
\end{abstract}

\section{Introduction}

The phosphatidylinositol-3-kinase (PI3K)/Akt signaling axis plays a pivotal role in regulating multiple cellular events including cell growth, survival, metabolism, and motility through the modulation of a plethora of downstream effectors. In response to growth factor or cytokine stimulation, activated PI3K facilitates the production of phosphatidylinositol 3,4,5-trisphosphate ( $\left.\mathrm{PIP}_{3}\right)$, leading to the membrane recruitment and subsequent activating phosphorylation of Akt at Thr-308 and Ser- 473 by phosphoinositide-dependent kinase (PDK)1 and PDK2, respectively. In contrast to the well-characterized PDK1 $1{ }^{1}$ the molecular identity of PDK2 remains elusive. ${ }^{2}$ Although recent evidence has suggested that the rictormTOR complex (mTORC2) acts as a PDK2, 3,4 a number of other kinases have also been implicated in mediating Akt-Ser-473 phosphorylation, ${ }^{2}$ one of which is integrin-linked kinase (ILK). ${ }^{5-7}$

ILK was originally identified as a binding partner of the cytoplasmic tail of integrin $\beta 1$ through a yeast two-hybrid screening. ${ }^{8}$ The ILK protein comprises three major domains, namely the $\mathrm{N}$-terminal ankyrin repeats, a central pleckstrin homology domain, and $\mathrm{C}$ -

\footnotetext{
*To whom correspondence should be addressed. Address: 336 Parks Hall, The Ohio State University, 500 West $12^{\text {th }}$ Avenue, Columbus, OH 43210. Tel: (614)-688-4008; Fax: (614)-688-8556; chen.844@ osu.edu.
} 
terminal kinase domain. ${ }^{9}$ Each of these domains plays a role in mediating ILK's biological functions through interaction with intracellular signaling proteins or $\mathrm{PIP}_{3}$. For example, ILK physically interacts with the cytoplasmic proteins PINCH and parvin to form the ternary ILK-PINCH-parvin complex, which serves as a molecular scaffold linking integrins with actin cytoskeleton ${ }^{10}$ and the microtubule network ${ }^{11}$ to modulate actin polymerization and mitotic spindle orientation, respectively. Although whether ILK contains a functional kinase domain remains a contentious issue, ${ }^{12}$ ILK has been shown to mediate the phosphorylation of a variety of signaling proteins, including Akt at Ser-473, glycogen synthase kinase (GSK) $3 \beta,{ }^{5-7,13}$ and myosin light chain (MLC). ${ }^{14,15}$ Moreover, ILK overexpression has been associated with the oncogenesis and tumor progression of many types of malignancies, including those of prostate, ${ }^{16}$ ovary, ${ }^{17}$ breast,${ }^{18}$ colon, ${ }^{19}$ pancreas, ${ }^{20}$ stomach, ${ }^{21}$ and liver. ${ }^{22}$ In light of its role in regulating diverse cellular events, including cell proliferation, survival, angiogenesis, motility, and epithelial-mesenchymal transition, ILK represents a relevant target for cancer therapy. ${ }^{9}$ In this study, we report the identification and validation of a novel ILK inhibitor 22, which exhibits high potency in suppressing the viability of a panel of prostate and breast cancer cells $\left(\mathrm{IC}_{50}, 1-2.5 \mu \mathrm{M}\right)$ via autophagy and apoptosis. Our data indicate that this antiproliferative effect was, at least in part, attributable to the inactivation of Akt signaling and the transcriptional repression of the transcription factor Y-box binding protein (YB)-1 and its targets, including HER2 and EGFR. Equally important, daily oral 22 at 25 and $50 \mathrm{mg} / \mathrm{kg}$ was effective in suppressing PC-3 xenograft tumor growth in nude mice.

\section{Chemistry}

In the course of developing different kinase inhibitors, the authors' laboratory had used the scaffold of 4-(5-aryl-3-(trifluoromethyl)-1H-pyrazol-1-yl)aniline to generate an array of derivatives, ${ }^{23,24}$ designated as series A - C (Fig. 1). After preliminary modeling analysis by docking these compounds into the ATP binding pocket of ILK to assess binding affinities, additional derivatives were synthesized by replacing the $\mathrm{CF}_{3}$-side chain with a $-\mathrm{CONHCH}_{3}$ (series D and $\mathrm{N}$-methyl-1-(4-(piperazin-1-yl)phenyl)-5-(4'-(trifluoromethyl)-[1,1'biphenyl]-4-yl)-1 $\mathrm{H}$-pyrazole-3-carboxamide (21)) or - $\mathrm{CH}_{2} \mathrm{CH}_{2} \mathrm{CONHCH}_{3}$ moiety (series $\mathrm{E}$ and F, and $N$-methyl-3-(1-(4-morpholinophenyl)-5-(4'-(trifluoromethyl)-[1,1'-biphenyl]-4yl)-1 $H$-pyrazol-3-yl)propanamide (53)) to enhance hydrophilic interactions/hydrogen bonding with the peptide backbone of the binding site. General procedures for the syntheses of these new derivatives are depicted in Scheme 1. Together, these derivatives 1-53, were used for the biomolecular screening for ILK inhibitors by Western blot analysis of the effects of individual agents at $2.5 \mu \mathrm{M}$ on the phosphorylation level of Akt at Ser-473 versus Thr-308 in PC-3 cells.

\section{Results}

\section{Identification of putative PDK2 inhibitors by screening a focused compound library}

Of the 53 compounds examined, 22 and $N$-ethyl-3-(1-(4-(piperazin-1-yl)phenyl)-5-(4'(trifluoromethyl)-[1,1'-biphenyl]-4-yl)-1H-pyrazol-3-yl)propanamide (23) exhibited strong PDK2 inhibitory activity, i.e. selectivity in facilitating Akt Ser-473 dephosphorylation without affecting that of Thr-308, while other agents showed low or no appreciable activities in mediating Akt dephosphorylation at either residue (Fig. 2A). As these two structurally related compounds differ only in the $N$-alkyl moiety, i.e., methyl versus ethyl, 22 was used as the lead agent for mechanistic validation.

Structure-activity relationship analysis revealed a stringent structural requirement for the Akt Ser-473 dephosphorylating activity of 22, for which the integrity of the three peripheral structural motifs, i.e., 4-trifluoromethyl-biphenyl moiety (motif a), $N$-methylpropanamide side chain (motif b), and piperazine ring (motif c), was critical (Fig. 2B). As such, minor 
modifications of any of these three motifs resulted in loss of the PDK2 inhibitory activity at $2.5 \mu \mathrm{M}$ : motif a: substituting the $\mathrm{CF}_{3}$-with a -CN (3-(5-(4'-cyano-[1,1'-biphenyl]-4-yl)-1-(4(piperazin-1-yl)phenyl)-1H-pyrazol-3-yl)- $N$-methylpropanamide (5)) or replacing it with a phenanthrene ring ( $N$-methyl-3-(5-(phenanthren-2-yl)-1-(4-(piperazin-1-yl)phenyl)-1 $H$ pyrazol-3-yl)propanamide (14)); motif b: replacing it with a $\mathrm{CF}_{3}$-moiety (1-(4-(3(trifluoromethyl)-5-(4'-(trifluoromethyl)-[1,1'-biphenyl]-4-yl)-1H-pyrazol-1-

yl)phenyl)piperazine (6)) or shortening the side chain length by two carbon units (21); motif c: replacing it with a $\beta$-alanine (3-amino- $N$-(4-(3-(3-(methylamino)-3-oxopropyl)-5-(4'(trifluoromethyl)-[1,1'-biphenyl]-4-yl)-1H-pyrazol-1-yl)phenyl)propanamide (18)) or substituting the nitrogen atom with an oxygen $(\mathbf{5 3})$.

\section{Compound 22 exhibits high antiproliferative potency}

The antitumor effects of $\mathbf{2 2}$ were examined in a panel of prostate and breast cancer cell lines with varying genetic defects and compared to the effect in normal prostate epithelial cells (PrECs) and mammary epithelial cells (MEC) by MTT assays (Fig. 3A). Compound 22 differentially suppressed the viability of these cancer cells with the following $\mathrm{IC}_{50}$ values: prostate cancer cells: LNCaP, $1.6 \mu \mathrm{M}$; PC-3, $2 \mu \mathrm{M}$; breast cancer cells: MDA-MB-231, 1 $\mu \mathrm{M}$; MDA-MB-468, $1.5 \mu \mathrm{M}$; SKBR3, $1.8 \mu \mathrm{M}$; MCF-7, $2.5 \mu \mathrm{M}$. In contrast, PrECs and MECs were resistant to the antiproliferative effect of 22 within the dose range of $1-5 \mu \mathrm{M}$.

\section{Evidence that 22 is an ILK inhibitor}

The PDK2 inhibitory activity of $\mathbf{2 2}$ was confirmed by its dose-dependent suppressive effect on Akt phosphorylation at Ser-473 without disturbing that of Thr-308 in PC-3 and MDAMB-231 cells (Fig. 3B). It is noteworthy that this drug-induced Ser-473-Akt dephosphorylation was accompanied by parallel decreases in the phosphorylation levels of GSK3 $\beta$ and MLC, two downstream targets of ILK, while those of the mTORC2 substrates serum- and glucocorticoid-induced protein kinase (SGK)- $1^{25}$ and protein kinase $\mathrm{C}$ (PKC) $\alpha^{26}$ were unaffected (Fig. 3B). As a positive control, shRNA-mediated knockdown of ILK in PC- 3 cells modulated the phosphorylation of these signaling proteins in a manner similar to that of 22. Together, these findings suggest that $\mathbf{2 2}$ might mediate Ser-473-Akt dephosphorylation through the inhibition of ILK.

This premise was corroborated by the dose-dependent inhibitory effect of 22 on the phosphorylation of myelin basic protein (MBP), a known ILK substrate, ${ }^{5}$ by immunoprecipitated ILK in an in vitro radiometric kinase assay. Representative autoradiographic data from one of several experiments are shown in Fig. 4A, of which the densitometric analysis indicates an $\mathrm{IC}_{50}$ of $0.6 \mu \mathrm{M}$. Moreover, the stable expression of GFPtagged constitutively active (CA)-ILK in PC-3 cells increased phosphorylation of Ser-473Akt and GSK3 $\beta$, while the levels of p-Thr-308-Akt, p-PKC $\alpha$, and p-GSK1 remained unaltered (Fig. 4B, left panel). In addition, this overexpression of CA-ILK protected PC-3 cells from 22-mediated inhibition of cell viability as indicated by MTT assays showing a shift in the dose-response curve for CA-ILK-overexpressing PC-3 cells to the right (Fig. 4B, right panel).

\section{Compound 22 suppressed the expression of YB-1 and its targets HER2 and EGFR via an ILK-dependent mechanism}

Suppression of ILK by either siRNA-mediated knockdown or pharmacological inhibition has been shown to reduce the expression of several growth factor receptors, including HER2 and EGFR, ${ }^{27,28}$ in breast cancer cells by down-regulating the expression of the shared transcriptional/translational regulator YB-1. Pursuant to these findings, we examined the ability of $\mathbf{2 2}$ to modulate the expression of these important signaling effectors in PC-3 and SKBR3 cells. Western blot and RT-PCR analyses indicate that $\mathbf{2 2}$ reduced the expression of 
YB-1, HER2, and EGFR, at both protein and transcript levels, in a dose-dependent manner in both cell lines (Fig. 5A, PC-3; B, SKBR3). Equally important, overexpression of CAILK, through stable and transient transfection in PC-3 and SKBR3 cells, respectively, diminished the suppressive effect of $\mathbf{2 2}$ on these signaling effectors.

\section{Specificity in kinase inhibition}

To assess the specificity of 22's kinase inhibitory activity, the compound was evaluated against a panel of 20 recombinant kinases by kinase-profiling assays performed by a commercial vendor (Millipore, Billerica, MA). The results support a high degree of specificity of $\mathbf{2 2}$ for ILK as the remaining activities of the individual kinases in the profile after exposure to $5 \mu \mathrm{M} 22$ were high ( $\geq 65 \%)$ : Abl, 73\%; CDK1/cyclin B, 73\%; CDK5/p25, 98\%; cKit, 100\%; cSRC, 91\%; EGFR, 103\%; Flt3, 66\%; GSK3 $\beta, 142 \%$; IKK $\beta, 102 \%$; Jak2, 114\%; Jak3, 128\%; Met, 110\%; mTOR, 122\%; PDK1, 94\%; Akt, 88\%; PKCa, 97\%; Ros, 103\%; Rsk1, 65\%; ZAP70, 104\%. Among the 19 recombinant kinases examined, the only exception was p70S6K, which exhibited greater than 50\% inhibition by $\mathbf{2 2}$ (44\% residual activity after treatment). This finding was confirmed by Western blot analysis of the dosedependent effects of $\mathbf{2 2}$ on the phosphorylation of p70S6K versus its target S6 in PC-3 cells (Fig. 6A). As shown, 22 exhibited a modest suppressive effect on phosphorylated S6 levels, without affecting the phosphorylation status of p70S6K, an mTOR substrate. Moreover, in contrast to the reported effects of the known ILK inhibitor $(E)$-4-(substitutedphenyl)diazenyl-1,3,5-substituted- $1 H$-pyrazole 54 (QLT0267), ${ }^{29} 22$ did not affect the autophosphorylation of focal adhesion kinase (FAK) at Tyr-397, a marker of FAK inhibition. ${ }^{30}$ In addition, as evidence suggests the intermediary role of ILK in mediating growth factor/ integrin-induced activation of ERKs ${ }^{31-34}$ or $\mathrm{p}^{38^{35-38}}$ in various cell systems, we investigated the phosphorylation status of ERKs and p38 versus JNKs in $\mathbf{2 2}$-treated cells. As shown in Fig. 6A, of the three MAP kinases evaluated, 22 showed dose-dependent suppressive effects on the levels of phospho-ERK1/2 and phospho-p38, while that of phospho-JNK remained unaltered. Equally important, stable expression of CA-ILK prevented 22-facilitated inhibition of ERK and p38 phosphorylation, supporting the functional role of ILK in regulating the activation of ERKs and p38 in PC-3 cells (Fig. 6B). In contrast, CA-ILK showed no protective effect on the downregulation of S6 phosphorylation, confirming that 22 cross-inhibited p70S6K.

\section{Compound 22 causes cell death through autophagy and apoptosis}

To shed light onto the mode of antiproliferative action of 22, we assessed its effects on cell cycle progression and programmed cell death (apoptosis versus autophagy) in PC-3 cells. Flow cytometric analyses of cell cycle and Annexin V staining indicate no apparent changes in cell cycle distribution or induction of apoptosis until the $\mathbf{2 2}$ concentration exceeded a threshold of $2 \mu \mathrm{M}$ (Fig. 7A \& B). Western blot analysis of PARP cleavage and LC3-II conversion revealed that $\mathbf{2 2}$ induced both apoptosis and autophagy, and that the occurrence of drug-induced autophagy preceded that of apoptosis in the dose-response relationship (Fig. 7C). As shown, 22-induced accumulation of LC3-II, an essential step for autophagosome formation, was evident at concentrations as low as $1 \mu \mathrm{M}$, while PARP cleavage occurred at $\geq 2 \mu \mathrm{M}$. In addition, this induction of autophagy was blocked by the stable expression of CA-ILK, suggesting that 22-induced autophagy was attributable to ILK inhibition (Fig. 7D).

Autophagy plays a dichotomous role in mediating cell fates, either protective or destructive, in response to metabolic stress or therapeutic agents. ${ }^{39}$ In this context, we examined the effect of siRNA-mediated knockdown of autophagy-related 5 homolog (Atg5) on 22mediated suppression of PC-3 cell viability. As shown, silencing of Atg5 disrupted 22induced LC3-II processing, and attenuated drug-induced cytotoxicity in PC-3 cells (Fig. 7E). 
This finding suggests that the induction of autophagy represents a mechanism by which $\mathbf{2 2}$ mediates its antiproliferative activity, especially at low concentrations.

\section{Suppressive effect of oral 22 on PC-3 xenograft tumor growth}

The in vivo antitumor efficacy of $\mathbf{2 2}$ was evaluated in an ectopic PC-3 tumor xenograft model. Athymic nude mice bearing established subcutaneous PC-3 tumors were treated with oral 22 once daily at 25 and $50 \mathrm{mg} / \mathrm{kg}$ or the vehicle control. The daily administration of $\mathbf{2 2}$ at both doses was well tolerated as the mice showed no overt signs of toxicity or loss of body weight (data not shown). Treatment with oral $\mathbf{2 2}$ in either dose resulted in significant suppression $(P<0.05)$ of tumor growth relative to the vehicle control after 35 days of treatment (48\% and 62\% suppression for 25 and $50 \mathrm{mg} / \mathrm{kg}$, respectively; Fig. 8A). Examinations of intratumoral markers associated with drug activity in three representative tumor lysates from each group showed a dose-dependent inhibition of the phosphorylation of Ser-473-Akt, while that of Thr-308-Akt was unaffected, accompanied by parallel decreases in the phosphorylation levels of GSK3 $\beta$ and MLC and in the expression levels of YB-1, HER2, and EGFR (Fig. 8B). Together, the modulation of these biomarkers validates ILK inhibition as at least part of the in vivo mode of antitumor action of 22.

\section{Discussion}

Although substantial evidence has demonstrated the pivotal role of ILK in regulating diverse cellular functions pertinent to motility, proliferation, survival, and angiogenesis, a key issue that remains in dispute is whether ILK possesses functional kinase activity or serves as an adaptor protein to mediate these cellular responses. ${ }^{12}$ Numerous studies, including the work described here, have demonstrated that siRNA-mediated silencing or pharmacological inhibition of ILK in various types of normal and malignant cells led to decreased phosphorylation of Ser-473-Akt and GSK3 $\beta$. Moreover, substantial evidence has demonstrated the oncogenic role of ILK, reflected in the term of "ILK addiction" 40 in many types of cancers. ${ }^{16-22}$ Equally important, the ILK inhibitor $\mathbf{5 4}$ provides a proof-of-concept that ILK kinase activity can be targeted to suppress tumor cell growth via inhibition of signaling pathways mediated by Akt and YB-1. ${ }^{27,28,40}$ However, as recent reports indicate that 54 as a single agent lacks in vivo antitumor activity, ${ }^{41}$ and that it is not specific for ILK, ${ }^{29}$ there is an urgency to develop novel ILK inhibitors with higher potency and specificity.

Compound 22 was first identified through the screening of an in-house focused compound library by immunoblotting against Akt phosphorylation at Ser-473 versus Thr-308. Radiometric assays using immunoprecipitated ILK from PC-3 cells demonstrated the ability of 22 to inhibit ILK kinase activity with $\mathrm{IC}_{50}$ of $0.6 \mu \mathrm{M}$ (Fig. 4), which correlated with its high potency in suppressing the phosphorylation levels of Ser-473-Akt and other ILK substrates in cancer cells (Fig. 3). Equally important, 22 exhibited a high degree of specificity against a panel of recombinant kinases. Specifically, no appreciable inhibition by 22 was noted in a series of signaling kinases, including PDK1, Akt, mTOR, GSK3 $\beta$, FAK, cKit, EGFR, and FAK. An additional line of evidence for the ILK-targeted activity of $\mathbf{2 2}$ was its repressive effect on the mRNA and protein levels of the transcription/translation factor YB-1 and its representative targets HER2 and EGFR (Fig. 5). As elevated expression and nuclear localization of YB-1 is associated with increased proliferation, multidrug resistance, tumor aggressiveness, and poor prognosis in many types of cancers by stimulating the expression of a wide array of growth-promoting genes, ${ }^{42}$ the ability of 22 to target YB-1 expression is noteworthy.

Evidence suggests that $\mathbf{2 2}$ mediates its antiproliferative effect through the induction of both autophagy and apoptosis in PC-3 cells (Fig. 7). Our data indicate that 22 induced autophagy 
through ILK inhibition, which occurred at concentrations below the threshold $(2 \mu \mathrm{M})$ that our results show is required for activating apoptosis in 22-treated cells. Moreover, as Atg5 silencing attenuated autophagy and the suppressive effect of $\mathbf{2 2}$ on cell viability (Fig. 7E), this autophagy induction is integral to 22's antiproliferative activity, especially at low concentrations. Taken together, this broad spectrum of mechanisms underlies the therapeutic potential of $\mathbf{2 2}$ in cancer treatment, as manifested by its in vivo efficacy as a single agent in suppressing PC-3 xenograft tumor growth (Fig. 8).

In conclusion, our data demonstrate that $\mathbf{2 2}$ is a novel, orally bioavailable ILK inhibitor with a distinct mode of action that inhibits tumor cell growth by modulating multiple signaling pathways associated with oncogenesis and tumor progression. Evaluation of the ability of $\mathbf{2 2}$ to block EMT and other aspects of the aggressive phenotype, and the use of $\mathbf{2 2}$ as a lead compound for structural optimization to develop more potent ILK inhibitors are underway.

\section{Experimental Section}

Chemical reagents and organic solvents were purchased from Sigma-Aldrich (St. Louis, MO) unless otherwise mentioned. Nuclear magnetic resonance spectra ( ${ }^{1} \mathrm{H}$ NMR) were measured on a Bruker DPX 300 model spectrometer. Microwave reactions were carried out with the CEM Discover SP-D pressurized microwave digestion system (CEM Corp., Matthews, NC). Chemical shifts $(\delta)$ were reported in parts per million (ppm) relative to the TMS peak. Electrospray ionization mass spectrometry analyses were performed with a Micromass Q-Tof II high-resolution electrospray mass spectrometer in The Ohio State University Campus Chemical Instrument Center. The purities of all tested compounds are higher than $95 \%$ by elemental analyses, which were performed by Atlantic Microlab, Inc. (Norcross, GA), and were reported to be within $0.4 \%$ of calculated values. Flash column chromatography was performed using silica gel (230-400 mesh). Compounds of series A $\mathrm{C}$ were synthesized according to slight modifications of previously reported procedures..$^{23,24}$ The general procedures for the synthesis of compounds with carboxamide and propanamide side chains (series D - F, 21 and $\mathbf{5 3}$ ) are described in Fig. 2, which is illustrated by the synthesis of the lead ILK inhibitor $\mathbf{2 2}$ as an example.

\section{N-Methyl-3-(1-(4-(piperazin-1-yl)phenyl)-5-(4'-(trifluoromethyl)-[1,1'-biphenyl]-4-yl)-1 H- pyrazol-3-yl)propanamide (22)}

Step a-(4'-(Trifluoromethyl)-phenyl)boronic acid (4.7 g, $25 \mathrm{mmol})$ was added to a solution of 4-bromo-acetophenone ( $5 \mathrm{~g}, 25.1 \mathrm{mmol}, 1$ equiv), palladium (II) acetate (125 $\mathrm{mg}, 2 \mathrm{~mol} \%)$, potassium carbonate $(10.4 \mathrm{~g}, 75.3 \mathrm{mmol})$, and tetrabutylammonium bromide $(10.5 \mathrm{~g}, 32.6 \mathrm{mmol})$. The reaction mixture was added water $(250 \mathrm{ml})$, heated to $60{ }^{\circ} \mathrm{C}$ with stirring for $2 \mathrm{~h}$ under argon, cooled, diluted with water, and extracted with ethyl acetate. The organic layer was dried and concentrated, and the residue was purified by flash column chromatography (ethyl acetate-hexane, 3:7) to afford 1-(4'-(trifluoromethyl)-[1,1'biphenyl]-4-yl)ethanone (i) in quantitative yield. ${ }^{1} \mathrm{H}$ NMR $\left(300 \mathrm{MHz}, \mathrm{CDCl}_{3}\right) \delta 2.66$ (s, 3H), $7.72(\mathrm{~m}, 6 \mathrm{H}), 8.07(\mathrm{~d}, J=8.4 \mathrm{~Hz}, 2 \mathrm{H})$.

Step c-To a solution of compound i $(6.6 \mathrm{~g}, 25 \mathrm{mmol})$ in dry methylene chloride $(250 \mathrm{~mL})$ was added ethyl 4-(1H-benzo[d][1,2,3]triazol-1-yl)-4-oxobutanoate $(7.4 \mathrm{~g}, 30 \mathrm{mmol})$, magnesium bromide ethyl etherate $(13 \mathrm{~g}, 50 \mathrm{mmol})$ under argon. The resulting solution was stirred under argon for $10 \mathrm{~min}$, added dropwise $N, N$-diisopropylethylamine $(4.8 \mathrm{~mL}, 50$ $\mathrm{mmol})$, stirred for $16 \mathrm{~h}$, and washed, in tandem, with $10 \% \mathrm{HCl}(150 \mathrm{~mL} \times 1)$ and water (200 $\mathrm{mL} \times 2)$. The organic phase was dried and concentrated. The residue was purified by chromatography (ethyl acetate-hexane, 9/1), followed by recrystallization in ethanol to give (Z)-3-hydroxy-1-(4'-(trifluoromethyl)-[1,1'-biphenyl]-4-yl)oct-2-ene-1,6-dione (ii) as white crystal $\left(9.7 \mathrm{~g}, 99 \%\right.$ yield). ${ }^{1} \mathrm{H}$ NMR $\left(300 \mathrm{MHz}, \mathrm{CDCl}_{3}\right) \delta 1.31(\mathrm{t}, J=7.2 \mathrm{~Hz}, 3 \mathrm{H}), 2.72(\mathrm{t}, J$ 
$=7.2 \mathrm{~Hz}, 2 \mathrm{H}), 2.85(\mathrm{t}, J=7.2 \mathrm{~Hz}, 2 \mathrm{H}), 4.18(\mathrm{q}, J=7.2 \mathrm{~Hz}, 2 \mathrm{H}), 6.26(\mathrm{~s}, 1 \mathrm{H}), 7.68(\mathrm{~d}, J=$ $8.1 \mathrm{~Hz}, 2 \mathrm{H}), 7.74(\mathrm{~m}, 4 \mathrm{H}), 7.98(\mathrm{~d}, J=8.1 \mathrm{~Hz}, 2 \mathrm{H}), 15.82(\mathrm{~s}, 1 \mathrm{H})$.

Step d-To a solution of compound ii $(981 \mathrm{mg}, 2.5 \mathrm{mmol})$ in ethanol $(10 \mathrm{~mL})$ was added 4-nitro-phenylhydrazine hydrochloride $(570 \mathrm{mg}, 3 \mathrm{mmol}$ ) and 4-methylbenzene-sulfonic acid $(430 \mathrm{mg}, 2.5 \mathrm{mmol})$. The resulting solution was stirred under microwave at $120{ }^{\circ} \mathrm{C}$ for $10 \mathrm{~min}$, concentrated, and recrystallized in ethanol to give ethyl ethyl 3-(1-(4nitrophenyl)-5-(4'-(trifluoromethyl)-[1,1'-biphenyl]-4-yl)-1H-pyrazol-3-yl)propanoate (iii) as yellow crystal (866 mg, $72 \%$ yield). ${ }^{1} \mathrm{H}$ NMR $\left(300 \mathrm{MHz}, \mathrm{CDCl}_{3}\right) \delta 1.28(\mathrm{t}, J=7.2 \mathrm{~Hz}$, $3 \mathrm{H}), 2.77(\mathrm{t}, J=7.5 \mathrm{~Hz}, 2 \mathrm{H}), 3.17(\mathrm{t}, J=7.5 \mathrm{~Hz}, 2 \mathrm{H}), 4.18(\mathrm{q}, J=7.2 \mathrm{~Hz}, 2 \mathrm{H}), 6.69(\mathrm{~s}, 1 \mathrm{H})$, $7.69(\mathrm{~d}, J=8.1 \mathrm{~Hz}, 2 \mathrm{H}), 7.74(\mathrm{~m}, 4 \mathrm{H}), 7.81(\mathrm{~d}, J=8.4 \mathrm{~Hz}, 2 \mathrm{H}), 7.97(\mathrm{~d}, J=9.3 \mathrm{~Hz}, 2 \mathrm{H})$, $8.41(\mathrm{~d}, J=8.4 \mathrm{~Hz}, 2 \mathrm{H})$.

Step e-To a solution of compound iii (1 g, $2 \mathrm{mmol})$ in ethanol $(2 \mathrm{~mL})$ was added $1 \mathrm{M}$ methylamine in ethanol solution $(5 \mathrm{~mL})$. The resulting solution was heated to $120^{\circ} \mathrm{C}$ with stirring in a sealed tube for $16 \mathrm{~h}$ and concentrated, followed by recrystallization in ethanol to give $N$-methyl-3-(1-(4-nitrophenyl)-5-(4'-(trifluoromethyl)-[1,1'-biphenyl]-4-yl)- $1 \mathrm{H}$ pyrazol-3-yl)propanamide (iv) as yellow powder $(712 \mathrm{mg}, 70 \%) .{ }^{1} \mathrm{H}$ NMR $(300 \mathrm{MHz}$, $\left.\mathrm{CDCl}_{3}\right) \delta 2.60(\mathrm{t}, J=7.2 \mathrm{~Hz}, 2 \mathrm{H}), 2.80(\mathrm{~s}, 3 \mathrm{H}), 3.21(\mathrm{t}, J=7.2 \mathrm{~Hz}, 2 \mathrm{H}), 5.45(\mathrm{bs}, 1 \mathrm{H}), 6.66$ (s, 1H), $7.68(\mathrm{~m}, 2 \mathrm{H}), 7.73(\mathrm{~m}, 4 \mathrm{H}), 7.82(\mathrm{~d}, J=7.8 \mathrm{~Hz}, 2 \mathrm{H}), 7.96(\mathrm{~d}, J=6.9 \mathrm{~Hz}, 2 \mathrm{H}), 8.39$ (d, $J=8.4 \mathrm{~Hz}, 2 \mathrm{H})$.

Step $\mathbf{f}-$ To a solution of compound iv $(500 \mathrm{mg}, 1 \mathrm{mmol})$ in methanol-ethyl acetate $(1: 3,10$ $\mathrm{mL}$ ) was added $\mathrm{Pd}$ on activated charcoal $(15 \mathrm{mg})$. The resulting mixture was stirred under $\mathrm{H}_{2(\mathrm{~g})}$ at $70 \mathrm{psi}$ for $12 \mathrm{~h}$, filtered, and concentrated. The residue was then purified by chromatography ( $\left.\mathrm{MeOH}-\mathrm{CH}_{2} \mathrm{Cl}_{2}-\mathrm{NH}_{4} \mathrm{OH}, 1: 99: 0.1\right)$, followed by recrystallization in $\mathrm{CH}_{2} \mathrm{Cl}_{2}$ to give 3-(1-(4-aminophenyl)-5-(4'-(trifluoromethyl)-[1,1'-biphenyl]-4-yl)-1Hpyrazol-3-yl)- $N$-methylpropanamide (v) as white crystal (460 mg, 99\%.). ${ }^{1} \mathrm{H}$ NMR (300 $\left.\mathrm{MHz}, \mathrm{CDCl}_{3}\right) \delta 2.50(\mathrm{t}, J=7.5 \mathrm{~Hz}, 2 \mathrm{H}), 2.69(\mathrm{~s}, 3 \mathrm{H}), 2.91(\mathrm{t}, J=7.5 \mathrm{~Hz}, 2 \mathrm{H}), 6.82(\mathrm{~d}, J=$ $6.9 \mathrm{~Hz}, 2 \mathrm{H}), 7.19(\mathrm{~d}, J=8.4 \mathrm{~Hz}, 2 \mathrm{H}), 7.72(\mathrm{~m}, 4 \mathrm{H}), 7.83(\mathrm{~m}, 4 \mathrm{H})$.

Step i-To a solution of compound $\mathrm{v}(140 \mathrm{mg}, 0.3 \mathrm{mmol})$ in dry xylene $(10 \mathrm{~mL})$ was added bis(2-chloroethyl)amine hydrochloride $(62 \mathrm{mg}, 0.36 \mathrm{mmol})$. The resulting mixture and heated to $170^{\circ} \mathrm{C}$ with stirring for $20 \mathrm{~h}$, cooled, and concentrated. The residue was purified by chromatography (MeOH- $\left.\mathrm{CH}_{2} \mathrm{Cl}_{2}-\mathrm{NH}_{4} \mathrm{OH}, 2: 98: 0.1\right)$, followed by recrystallization in ethyl acetate to give $N$-methyl-3-(1-(4-(piperazin-1-yl)phenyl)-5-(4'-(trifluoromethyl)-[1,1'biphenyl]-4-yl)-1 $H$-pyrazol-3-yl)propanamide (22) as white powder $(80 \mathrm{mg}, 50 \%) .{ }^{1} \mathrm{H}$ NMR $\left(300 \mathrm{MHz}, \mathrm{CDCl}_{3}\right) \delta 2.45(\mathrm{dd}, J=8.0,7.4 \mathrm{~Hz}, 2 \mathrm{H}), 2.78(\mathrm{~d}, J=4.8 \mathrm{~Hz}, 3 \mathrm{H}), 3.01(\mathrm{~d}$, $J=8.0 \mathrm{~Hz}, 2 \mathrm{H}), 3.06(\mathrm{~m}, 4 \mathrm{H}), 3.21(\mathrm{dd}, J=6.2,3.6 \mathrm{~Hz}, 4 \mathrm{H}), 5.54(\mathrm{bs}, 1 \mathrm{H}), 6.54(\mathrm{~s}, 1 \mathrm{H})$, $6.98(\mathrm{~d}, J=8.9 \mathrm{~Hz}, 2 \mathrm{H}), 7.35(\mathrm{~d}, J=8.8 \mathrm{~Hz}, 2 \mathrm{H}), 7.64(\mathrm{~d}, J=8.3 \mathrm{~Hz}, 2 \mathrm{H}), 7.71(\mathrm{q}, J=8.6$ $\mathrm{Hz}, 4 \mathrm{H}), 7.93(\mathrm{~d}, J=8.3 \mathrm{~Hz}, 2 \mathrm{H})$. HRMS exact mass of $\mathrm{C}_{30} \mathrm{H}_{30} \mathrm{~F}_{3} \mathrm{~N}_{5} \mathrm{O}\left(\mathrm{M}+\mathrm{H}^{+}\right): 534.2480$ amu; found, 534.2467 amu. Anal. calcd C 67.53, H 5.67, F 10.68, N 13.13; found C 67.17, H 5.61, F 10.36, N 12.95 .

\section{3-(5-(4'-Cyano-[1,1'-biphenyl]-4-yl)-1-(4-(piperazin-1-yl)phenyl)-1 H-pyrazol-3-yl)- $N$ - methylpropanamide (5)}

${ }^{1} \mathrm{H}-\mathrm{NMR}\left(300 \mathrm{MHz}, \mathrm{CDCl}_{3}\right): \delta 2.47(\mathrm{t}, J=7.5 \mathrm{~Hz}, 2 \mathrm{H}), 2.80(\mathrm{~d}, J=4.7 \mathrm{~Hz}, 3 \mathrm{H}), 3.02(\mathrm{~d}, J$ $=8.2 \mathrm{~Hz}, 2 \mathrm{H}), 3.07(\mathrm{dd}, J=3.9,1.9 \mathrm{~Hz}, 4 \mathrm{H}), 3.27-3.18(\mathrm{~m}, 4 \mathrm{H}), 5.45(\mathrm{bs}, 1 \mathrm{H}), 6.55(\mathrm{~s}, 1 \mathrm{H})$, $7.00(\mathrm{~d}, J=8.8 \mathrm{~Hz}, 2 \mathrm{H}), 7.37(\mathrm{~d}, J=8.7 \mathrm{~Hz}, 2 \mathrm{H}), 7.63(\mathrm{~d}, J=8.4 \mathrm{~Hz}, 2 \mathrm{H}), 7.73(\mathrm{~m}, 4 \mathrm{H})$, $7.95(\mathrm{~d}, J=8.4 \mathrm{~Hz}, 2 \mathrm{H})$. HRMS exact mass of $\mathrm{C}_{30} \mathrm{H}_{30} \mathrm{~N}_{6} \mathrm{O}\left(\mathrm{M}+\mathrm{H}^{+}\right)$: $491.2559 \mathrm{amu}$; found: $491.2546 \mathrm{amu}$. 
N-Methyl-3-(5-(phenanthren-2-yl)-1-(4-(piperazin-1-yl)phenyl)-1 H-pyrazol-3-yl)propanamide (14)

${ }^{1} \mathrm{H}-\mathrm{NMR}\left(300 \mathrm{MHz}, \mathrm{CDCl}_{3}\right): \delta 2.49(\mathrm{t}, J=7.5 \mathrm{~Hz}, 2 \mathrm{H}), 2.80(\mathrm{~d}, J=4.6 \mathrm{~Hz}, 3 \mathrm{H}), 3.05(\mathrm{~m}$, $6 \mathrm{H}), 3.21(\mathrm{~m}, 4 \mathrm{H}), 5.49(\mathrm{bs}, 1 \mathrm{H}), 6.67(\mathrm{~s}, 1 \mathrm{H}), 7.00(\mathrm{~d}, J=8.6 \mathrm{~Hz}, 2 \mathrm{H}), 7.39(\mathrm{~d}, J=8.6 \mathrm{~Hz}$, $2 \mathrm{H}), 7.63(\mathrm{~m}, 2 \mathrm{H}), 7.76(\mathrm{q}, J=8.7 \mathrm{~Hz}, 2 \mathrm{H}), 7.89(\mathrm{~d}, J=7.7 \mathrm{~Hz}, 1 \mathrm{H}), 8.16(\mathrm{dd}, J=8.4,0.8$ $\mathrm{Hz}, 1 \mathrm{H}), 8.35(\mathrm{~m}, 1 \mathrm{H}), 8.71(\mathrm{dd}, J=4.8,3.7 \mathrm{~Hz}, 2 \mathrm{H})$. HRMS exact mass of $\mathrm{C}_{31} \mathrm{H}_{31} \mathrm{~N}_{5} \mathrm{O}(\mathrm{M}$ $\left.+\mathrm{H}^{+}\right): 490.2607 \mathrm{amu}$; found, $490.2625 \mathrm{amu}$.

1-(4-(3-Aminopropanamido)phenyl)- $\mathrm{N}$-methyl-5-(4'-(trifluoromethyl)-[1,1'-biphenyl]-4-yl)-1Hpyrazole-3-carboxamide (15)

${ }^{1} \mathrm{H}-\mathrm{NMR}\left(300 \mathrm{MHz}, \mathrm{CDCl}_{3}\right) \delta 2.84(\mathrm{t}, J=5.6 \mathrm{~Hz}, 2 \mathrm{H}), 2.93(\mathrm{~s}, 3 \mathrm{H}), 3.26(\mathrm{~d}, J=5.7 \mathrm{~Hz}$, 2H), $7.02(\mathrm{~s}, 1 \mathrm{H}), 7.33(\mathrm{~m}, 4 \mathrm{H}), 7.68(\mathrm{~m}, 6 \mathrm{H}), 7.80(\mathrm{~d}, J=8.0 \mathrm{~Hz}, 2 \mathrm{H})$. HRMS exact mass of $\mathrm{C}_{27} \mathrm{H}_{24} \mathrm{~F}_{3} \mathrm{~N}_{5} \mathrm{O}_{2}\left(\mathrm{M}+\mathrm{H}^{+}\right)$: $508.1960 \mathrm{amu}$; found, $508.1953 \mathrm{amu}$.

1-(4-(3-Aminopropanamido)phenyl)- $\mathrm{N}$-ethyl-5-(4'-(trifluoromethyl)-[1,1'-biphenyl]-4-yl)-1 Hpyrazole-3-carboxamide (16)

${ }^{1} \mathrm{H}-\mathrm{NMR}\left(300 \mathrm{MHz}, \mathrm{CDCl}_{3}\right) \delta 1.23(\mathrm{t}, J=7.1 \mathrm{~Hz}, 3 \mathrm{H}), 2.82(\mathrm{t}, J=6.0 \mathrm{~Hz}, 2 \mathrm{H}), 3.23(\mathrm{~m}$, $2 \mathrm{H}), 3.43(\mathrm{dd}, J=14.1,7.0 \mathrm{~Hz}, 2 \mathrm{H}), 7.04(\mathrm{~s}, 1 \mathrm{H}), 7.41-7.29(\mathrm{~m}, 4 \mathrm{H}), 7.76-7.62(\mathrm{~m}, 6 \mathrm{H})$, $7.81(\mathrm{~d}, J=8.2 \mathrm{~Hz}, 2 \mathrm{H})$. HRMS exact mass of $\mathrm{C}_{28} \mathrm{H}_{26} \mathrm{~F}_{3} \mathrm{~N}_{5} \mathrm{O}_{2}\left(\mathrm{M}+\mathrm{H}^{+}\right): 522.2117 \mathrm{amu}$; found: $522.2112 \mathrm{amu}$.

1-(4-(3-Aminopropanamido)phenyl)-N-isopropyl-5-(4'-(trifluoromethyl)-[1,1'-biphenyl]-4yl)-1 $H$-pyrazole-3-carboxamide (17)

${ }^{1} \mathrm{H}-\mathrm{NMR}\left(300 \mathrm{MHz}, \mathrm{CDCl}_{3}\right) \delta 1.18(\mathrm{~d}, J=6.3 \mathrm{~Hz}, 6 \mathrm{H}), 2.75(\mathrm{t}, J=5.8 \mathrm{~Hz}, 2 \mathrm{H}), 3.06(\mathrm{~m}$, $2 \mathrm{H}), 4.20(\mathrm{~m}, 1 \mathrm{H}), 7.04(\mathrm{~s}, 1 \mathrm{H}), 7.41-7.29(\mathrm{~m}, 4 \mathrm{H}), 7.76-7.62(\mathrm{~m}, 6 \mathrm{H}), 7.81(\mathrm{~d}, J=8.2 \mathrm{~Hz}$, $2 \mathrm{H})$. HRMS exact mass of $\mathrm{C}_{29} \mathrm{H}_{28} \mathrm{~F}_{3} \mathrm{~N}_{5} \mathrm{O}_{2}\left(\mathrm{M}+\mathrm{H}^{+}\right)$: $536.2273 \mathrm{amu}$; found, $536.2269 \mathrm{amu}$.

3-Amino-N-(4-(3-(3-(methylamino)-3-oxopropyl)-5-(4'-(trifluoromethyl)-[1,1'-biphenyl]-4yl)-1H-pyrazol-1-yl)phenyl)propanamide (18)

${ }^{1} \mathrm{H}-\mathrm{NMR}\left(300 \mathrm{MHz}, \mathrm{CDCl}_{3}\right) \delta 2.51(\mathrm{dd}, J=10.0,5.6 \mathrm{~Hz}, 2 \mathrm{H}), 2.69(\mathrm{~s}, 3 \mathrm{H}), 3.98(\mathrm{~m}, 2 \mathrm{H})$, $3.30(\mathrm{~m}, 2 \mathrm{H}), 3.48(\mathrm{~m}, 2 \mathrm{H}), 6.66(\mathrm{~s}, 1 \mathrm{H}), 6.82(\mathrm{~d}, J=8.3 \mathrm{~Hz}, 2 \mathrm{H}), 7.19(\mathrm{~d}, J=8.5 \mathrm{~Hz}, 2 \mathrm{H})$, $7.73(\mathrm{~m}, 4 \mathrm{H}), 7.86(\mathrm{~m}, 4 \mathrm{H})$. HRMS exact mass of $\mathrm{C}_{29} \mathrm{H}_{28} \mathrm{~F}_{3} \mathrm{~N}_{5} \mathrm{O}_{2}\left(\mathrm{M}+\mathrm{H}^{+}\right): 536.2273 \mathrm{amu}$; found: $536.2269 \mathrm{amu}$.

3-Amino-N-(4-(3-(3-(ethylamino)-3-oxopropyl)-5-(4'-(trifluoromethyl)-[1,1'-biphenyl]-4yl)-1H-pyrazol-1-yl)phenyl)propanamide (19)

${ }^{1} \mathrm{H}-\mathrm{NMR}\left(300 \mathrm{MHz}, \mathrm{CDCl}_{3}\right) \delta 1.08(\mathrm{t}, J=7.3 \mathrm{~Hz}, 3 \mathrm{H}), 2.54(\mathrm{t}, J=7.4 \mathrm{~Hz}, 2 \mathrm{H}), 2.88(\mathrm{t}, J=$ $6.3 \mathrm{~Hz}, 2 \mathrm{H}), 2.97(\mathrm{t}, J=7.3 \mathrm{~Hz}, 2 \mathrm{H}), 3.18(\mathrm{~m}, 2 \mathrm{H}), 3.30(\mathrm{~m}, 2 \mathrm{H}), 6.74(\mathrm{~s}, 1 \mathrm{H}), 7.50(\mathrm{~d}, J=$ $8.5 \mathrm{~Hz}, 2 \mathrm{H}), 7.74(\mathrm{~d}, J=8.3 \mathrm{~Hz}, 4 \mathrm{H}), 7.84(\mathrm{t}, J=7.1 \mathrm{~Hz}, 4 \mathrm{H}), 7.92(\mathrm{~d}, J=8.4 \mathrm{~Hz}, 2 \mathrm{H})$. HRMS exact mass of $\mathrm{C}_{30} \mathrm{H}_{30} \mathrm{~F}_{3} \mathrm{~N}_{5} \mathrm{O}_{2}\left(\mathrm{M}+\mathrm{H}^{+}\right)$: $550.2430 \mathrm{amu}$; found: $550.2429 \mathrm{amu}$.

3-Amino-N-(4-(3-(3-(isopropylamino)-3-oxopropyl)-5-(4'-(trifluoromethyl)-[1,1'-biphenyl]-4yl)-1H-pyrazol-1-yl)phenyl)propanamide (20)

${ }^{1} \mathrm{H}-\mathrm{NMR}\left(300 \mathrm{MHz}, \mathrm{CDCl}_{3}\right): \delta 1.12(\mathrm{~d}, J=6.6 \mathrm{~Hz}, 6 \mathrm{H}), 2.56(\mathrm{~m}, 2 \mathrm{H}), 2.91(\mathrm{~m}, 2 \mathrm{H}), 2.99$ $(\mathrm{m}, 2 \mathrm{H}), 4.95(\mathrm{~m}, 1 \mathrm{H}), 6.77(\mathrm{~s}, 1 \mathrm{H}), 7.53(\mathrm{~d}, J=8.7 \mathrm{~Hz}, 2 \mathrm{H}), 7.77(\mathrm{~d}, J=8.1 \mathrm{~Hz}, 4 \mathrm{H}), 7.87$ (t, $J=7.4 \mathrm{~Hz}, 4 \mathrm{H}), 7.95(\mathrm{~d}, J=8.5 \mathrm{~Hz}, 2 \mathrm{H})$. HRMS exact mass of $\mathrm{C}_{31} \mathrm{H}_{32} \mathrm{~F}_{3} \mathrm{~N}_{5} \mathrm{O}_{2}\left(\mathrm{M}+\mathrm{H}^{+}\right)$: $564.2586 \mathrm{amu}$; found: $564.2579 \mathrm{amu}$. 
N-Ethyl-1-(4-(piperazin-1-yl)phenyl)-5-(4'-(trifluoromethyl)-[1,1'-biphenyl]-4-yl)-1Hpyrazole-3-carboxamide (21)

${ }^{1} \mathrm{H}-\mathrm{NMR}\left(300 \mathrm{MHz}, \mathrm{CDCl}_{3}\right) \delta 1.26(\mathrm{t}, J=7.1 \mathrm{~Hz}, 3 \mathrm{H}), 3.05(\mathrm{~m}, 4 \mathrm{H}), 3.20(\mathrm{~m}, 4 \mathrm{H}), 3.51(\mathrm{~m}$, $2 \mathrm{H}), 6.92(\mathrm{~d}, J=8.6 \mathrm{~Hz}, 1 \mathrm{H}), 7.00(\mathrm{t}, J=5.4 \mathrm{~Hz}, 1 \mathrm{H}), 7.10(\mathrm{~s}, 1 \mathrm{H}), 7.23(\mathrm{~d}, J=8.4 \mathrm{~Hz}, 2 \mathrm{H})$, $7.35(\mathrm{~d}, J=7.9 \mathrm{~Hz}, 2 \mathrm{H}), 7.55(\mathrm{~d}, J=7.8 \mathrm{~Hz}, 2 \mathrm{H}), 7.69(\mathrm{~s}, 4 \mathrm{H})$. HRMS exact mass of $\mathrm{C}_{29} \mathrm{H}_{28} \mathrm{~F}_{3} \mathrm{~N}_{5} \mathrm{O}\left(\mathrm{M}+\mathrm{H}^{+}\right)$: $520.2324 \mathrm{amu}$; found, $520.2312 \mathrm{amu}$.

\section{N-Ethyl-3-(1-(4-(piperazin-1-yl)phenyl)-5-(4'-(trifluoromethyl)-[1,1'-biphenyl]-4-yl)-1 H- pyrazol-3-yl)propanamide (23)}

${ }^{1} \mathrm{H}-\mathrm{NMR}\left(300 \mathrm{MHz}, \mathrm{CDCl}_{3}\right) \delta 1.10(\mathrm{t}, J=7.3 \mathrm{~Hz}, 3 \mathrm{H}), 2.44(\mathrm{t}, J=7.7 \mathrm{~Hz}, 2 \mathrm{H}), 3.03(\mathrm{~m}$, $6 \mathrm{H}), 3.20(\mathrm{~m}, 4 \mathrm{H}), 3.28(\mathrm{~m}, 2 \mathrm{H}), 5.53(\mathrm{bs}, 1 \mathrm{H}), 6.54(\mathrm{~s}, 1 \mathrm{H}), 6.98(\mathrm{~d}, J=8.9 \mathrm{~Hz}, 2 \mathrm{H}), 7.35$ $(\mathrm{d}, J=8.8 \mathrm{~Hz}, 2 \mathrm{H}), 7.63(\mathrm{~d}, J=8.3 \mathrm{~Hz}, 2 \mathrm{H}), 7.71(\mathrm{q}, J=8.6 \mathrm{~Hz}, 4 \mathrm{H}), 7.93(\mathrm{~d}, J=8.3 \mathrm{~Hz}$, 2H). HRMS exact mass of $\mathrm{C}_{31} \mathrm{H}_{32} \mathrm{~F}_{3} \mathrm{~N}_{5} \mathrm{O}\left(\mathrm{M}+\mathrm{H}^{+}\right)$: $548.2637 \mathrm{amu}$; found, $548.2623 \mathrm{amu}$. Anal. calcd C 67.99, H 5.89, F 10.41, N 12.79; found C 67.67, H 5.83, F 10.16, N 12.63.

\section{N-Methyl-3-(1-(4-morpholinophenyl)-5-(4'-(trifluoromethyl)-[1,1'-biphenyl]-4-yl)-1 H- pyrazol-3-yl)propanamide (53)}

${ }^{1} \mathrm{H}-\mathrm{NMR}\left(300 \mathrm{MHz}, \mathrm{CDCl}_{3}\right) \delta 2.47(\mathrm{t}, J=7.5 \mathrm{~Hz}, 2 \mathrm{H}), 2.78(\mathrm{~d}, J=4.8 \mathrm{~Hz}), 3.03(\mathrm{~m}, 2 \mathrm{H})$, $3.22(\mathrm{~m}, 4 \mathrm{H}), 3.90(\mathrm{~m}, 4 \mathrm{H}), 5.49(\mathrm{bs}, 1 \mathrm{H}), 6.54(\mathrm{~s}, 1 \mathrm{H}), 6.98(\mathrm{~d}, J=8.7 \mathrm{~Hz}, 2 \mathrm{H}), 7.38(\mathrm{~d}, J=$ $8.4 \mathrm{~Hz}, 2 \mathrm{H}), 7.64(\mathrm{~d}, J=8.1 \mathrm{~Hz}, 2 \mathrm{H}), 7.72(\mathrm{q}, J=8.7 \mathrm{~Hz}, 4 \mathrm{H}), 7.94(\mathrm{~d}, J=8.1 \mathrm{~Hz}, 2 \mathrm{H})$. HRMS exact mass of $\mathrm{C}_{30} \mathrm{H}_{29} \mathrm{~F}_{3} \mathrm{~N}_{4} \mathrm{O}_{2}\left(\mathrm{M}+\mathrm{Na}^{+}\right)$: $557.2140 \mathrm{amu}$; measured mass, 557.2144 amu.

\section{Reagents and antibodies}

For in vitro studies, stock solutions of the test agents were made in DMSO and diluted in culture medium to a final DMSO concentration of $0.1 \%$. For administration to nude mice, agents were prepared as suspensions in sterile water containing $0.5 \%$ methylcellulose and $0.1 \%$ Tween 80 . The target proteins and commercial sources of antibodies used in the study

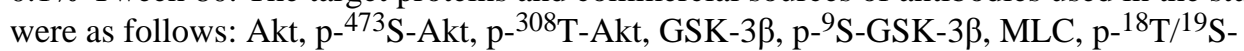
MLC, LC3, EGFR, ATG5, GFP, PCK $\alpha$ (Cell Signaling Technology, Inc., Beverly, MA), p- ${ }^{422}$ S-SGK1, YB-1 (Abcam, Inc., Cambridge, MA), p- ${ }^{657}$ S-PCK $\alpha$ (Millipore, Billerica, MA), HER2, c-Met, SGK1 (Santa Cruz Biotechnology, Inc., Santa Cruz, CA), $\beta$-actin (MP Biomedicals, Irvine, CA). The shRNA for ILK in the pLKO.1 vector was purchased from Sigma-Aldrich (St. Louis, MO). The human ILK full-length cDNA in the pCMV-SPORT6 vector was purchased from Thermo Scientific (Rockford, IL). GFP-tagged CA-ILK (constitutively active form S343D) was constructed from the human ILK full-length cDNA by site-directed mutagenesis and inserted into the pEGFP-C1 vector. Control siRNA and ATG5 siRNA were purchased from Cell Signaling Technology (Danvers, MA).

\section{Cell culture}

All cancer cells were purchased from the American Type Culture Collection (Manassas, VA). The PC-3 and LNCaP prostate cancer cells were maintained in RPMI 1640 medium, MDA-MB-231 and MDA-MB-468 breast cancer cells in DMEM medium, and SKBR3 and MCF7 breast cancer cells in DMEM/F12 medium, all supplemented with 10\% FBS. Nonmalignant human epithelial cells of the prostate (PrEC) and mammary gland (MEC) were obtained from Lonza Biologics, Inc. (Hopkinton, MA) and maintained in the defined growth medium obtained from the vendor. All cells were cultured at $37^{\circ} \mathrm{C}$ in a humidified incubator containing $5 \% \mathrm{CO}_{2}$. 


\section{Transfection and generation of stable sublines}

Cancer cells were transfected with plasmids or siRNA by electroporation using the Cell Line Nucleofector Kit of the Amaxa Nucleofector system (Lonza) according to manufacturer's instructions. Transient transfectants (expressing ILK shRNA, Atg5 siRNA, or GFP-CA-ILK [SKBR3]) were used for experiments $48 \mathrm{~h}$ after transfection. Stable PC-3 clones expressing GFP-CA-ILK or GFP were selected after one week exposure to G418 $(250 \mu \mathrm{g} / \mathrm{mL})$ by sorting for GFP signal on a FACSAria cell sorter (BD Biosciences, Franklin Lakes, NJ).

\section{Cell viability assay}

Cell viability was determined using the 3-(4,5-dimethylthiazol-2-yl)-2,5-

diphenyltetrazolium bromide) (MTT) assay. The assay was performed in 96-well plates in which cancer cells were seeded at 5000 cells/well and nonmalignant cells at 8000 cells/well in the presence of $10 \%$ FBS $24 \mathrm{~h}$ prior to treatment. Cells were then treated with compounds for $24 \mathrm{~h}$ in the presence of 5\% FBS. One-fourth volume of medium containing a $5 \mathrm{X}$ concentration of MTT $(0.25 \mathrm{mg} / \mathrm{mL})$ was added to each well followed by incubation at $37^{\circ} \mathrm{C}$ for $1 \mathrm{~h}$. After removal of medium, the reduced MTT dye in each well was solubilized in 100 $\mu \mathrm{l}$ of DMSO, and absorbance was measured at $570 \mathrm{~nm}$.

\section{Immunoblotting}

Treated cells were collected by scraping followed by centrifugation, washed once with cold phosphate-buffered saline (PBS), and then lysed in lysis buffer, consisting of $1 \%$ sodium dodecyl sulfate (SDS), $10 \mathrm{mM}$ ethylenediaminetetraacetic acid (EDTA) and $50 \mathrm{mM}$ Tris$\mathrm{HCl}(\mathrm{pH}$ 8.1), in the presence of a protease inhibitor cocktail (Sigma-Aldrich). Lysates were sonicated for $10 \mathrm{~s}$, and then centrifuged at $13,200 \times \mathrm{g}$ for $15 \mathrm{~min}$. Protein concentrations of the supernatants were determined using a colorimetric bicinchoninic acid assay (Pierce, Rockford, IL). An equivalent volume of 2X SDS-polyacrylamide gel electrophoresis sample loading buffer (300 mM Tris-HCl, pH 6.8; 10\% SDS; 5\% $\beta$-mercaptoethanol; 50\% glycerol and $0.05 \%$ bromophenol blue) was added to each sample, which were then was incubated in boiling water for $10 \mathrm{~min}$. Equal amounts of protein were resolved in SDS-polyacrylamide gels in a minigel apparatus and then transferred to nitrocellulose membranes. After blocking with Tris-buffered saline containing $0.1 \%$ Tween 20 (TBST) and 5\% non-fat milk for 40 min, the membrane was washed three times with TBST for a total of $30 \mathrm{~min}$ and then incubated with primary antibody at 1:1000 dilution in TBST at $4{ }^{\circ} \mathrm{C}$ for $2 \mathrm{~h}$. The membrane was again washed three times with TBST for a total of $30 \mathrm{~min}$, and then incubated with goat anti-rabbit or anti-mouse immunoglobulin G-horseradish peroxidase conjugates (1:5000) for $1 \mathrm{~h}$ at room temperature. After a final three washes, the proteins were then visualized by enhanced chemiluminescence.

\section{RNA extraction and RT-PCR}

Total RNA was isolated from PC3, PC-3/CA-ILK, SKBR3, and SKBR3/CA-ILK cells $(1 \times$ $10^{6}$ cells) using Trizol reagent (Invitrogen Corporation, Carlsbad, CA). Aliquots of $1 \mu \mathrm{g}$ of total RNA from each sample were reverse-transcribed to cDNA using the iScript cDNA Synthesis Kit (Bio-Rad Laboratories, Hercules, CA). PCR products were resolved by electrophoresis in $2 \%$ agarose gels and visualized by ethidium bromide staining. The sequences of primers used for RT-PCR were as follows.

YB-1: forward primer, 5'-AAGTGATGGAGGGTGCTGAC-3'; reverse primer 5'-TTCTTCATTGCCGTCCTCTC-3'. HER2: forward primer, 5'-TCCTGTGTGGACCTGGATGAC-3'; reverse primer, 5'-CCAAAGACCACCCCCAAGA-3'; EGFR: forward primer, 5'GGACGACGTGGTGGATGCCG-3'; EGFR: reverse primer, 5'-GGCGCC- 
TGTGGGGTCTGAGC-3'; $\beta$-actin: forward primer, 5'-CACGAAACTACCTTCAACTCCA-3'; reverse primer, 5'-GAAGCATTTGCGGTGGACGAT-3'.

\section{Radiometric ILK kinase assay}

The kinase activity of immunoprecipitated ILK was determined in an in vitro radiometric kinase assay using myelin basic protein (MBP) as substrate and $\left[\gamma_{-}{ }^{32} \mathrm{P}\right]$ ATP as phosphate donor according reported procedures 6,8 with modifications. For immunoprecipitation, PC-3 cells were pre-treated with EGF $(100 \mathrm{ng} / \mathrm{mL})$ for $2 \mathrm{~h}$, and then lysed $\left(5 \times 10^{5} / \mathrm{sample}\right)$ in 250 $\mu \mathrm{L}$ of lysis buffer (20 mM Tris-HCl [pH 7.5), $150 \mathrm{mM} \mathrm{NaCl}, 1 \%$ Triton X-100) for $2 \mathrm{~h}$ on ice. After sonication of lysates and centrifugation $(13,200 \times \mathrm{g}, 15 \mathrm{~min})$, aliquots of the supernatants were combined with $3 \mu \mathrm{L}$ ILK antibody and $15 \mu \mathrm{L}$ of protein A/G PLUSagarose (Santa Cruz). Immunocomplexes containing immunoprecipitated ILK (A/G PLUSILK) were then collected by centrifugation. Kinase activity assays were performed in $25 \mu \mathrm{L}$ kinase reaction buffer (Cell Signaling) containing $5 \mu \mathrm{g}$ of MBP and $2.5 \mu \mathrm{Ci}\left[\gamma^{3}{ }^{32} \mathrm{P}\right] \mathrm{ATP}$ $(3000 \mathrm{Ci} / \mathrm{mmol}, 10 \mathrm{mCi} / \mathrm{ml}$; Perkin Elmer, Waltham, MA), with and without $15 \mu \mathrm{L}$ of A/G PLUS-ILK. Reactions were incubated at $30^{\circ} \mathrm{C}$ for $25 \mathrm{~min}$, and stopped by addition of SDSPAGE sample buffer. Proteins were resolved on $15 \%$ SDS-polyacrylamide gels and $\left[\gamma_{-}{ }^{32} \mathrm{P}\right]$ MBP was detected by autoradiography. Densitometric analysis was performed to determine the relative intensities in drug-treated samples versus those in the respective DMSO-treated controls.

\section{Flow cytometry}

After $48 \mathrm{~h}$ treatment with 22, both adhered and unattached PC-3 cells were harvested, resuspended in ice-cold PBS $\left(1 \times 10^{6}\right.$ cells $\left./ 200 \mu \mathrm{L}\right)$ and then fixed with $1 \mathrm{~mL} 100 \%$ ethanol. For cell cycle analysis, fixed cells were pelleted, resuspended in $500 \mu \mathrm{L}$ propidium iodide (PI) staining solution ( $80 \mu \mathrm{g} / \mathrm{mL}$ PI, $100 \mu \mathrm{g} / \mathrm{mL}$ RNase, $0.1 \%$, v/v, Triton X-100 in PBS) at $37^{\circ} \mathrm{C}$ for $30 \mathrm{~min}$ in darkness, and then filtered through a $40 \mu \mathrm{m}$ nylon mesh. For assessment of apoptosis, cells were co-stained with FITC-conjugated annexin V and PI according to manufacturer's instructions. The distribution of cells among the phases of the cell cycle and numbers of apoptotic cells were determined using a FACSCalibur (BD Biosciences) flow cytometer and FlowJo software (Tree Star, Inc., Ashland, OR) for analysis.

\section{PC-3 xenograft tumor model}

Xenograft tumors were established in male $\mathrm{NCr}$ athymic nude mice $(5-7$ weeks of age; National Cancer Institute, Frederick, MD) by subcutaneous injection of $0.5 \times 10^{6}$ PC-3 cells in a total volume of $0.1 \mathrm{ml}$ serum-free medium containing 50\% Matrigel (BD Biosciences). Mice with established tumors $\left(157.1 \pm 29.1 \mathrm{~mm}^{3}\right)$ were randomized to three groups $(\mathrm{n}=6)$ receiving single daily treatments of 22 at 25 or $50 \mathrm{mg} / \mathrm{kg}$, or vehicle $(0.5 \%$ methylcellulose, $0.1 \%$ Tween 80 in water) for 35 days by oral gavage at a volume of $10 \mu \mathrm{l} / \mathrm{g}$ body weight. Tumor volumes were calculated from weekly caliper measurements using a standard formula $\left(\right.$ volume $=$ width $^{2} \times$ length $\times 0.52$ ). Body weights were measured weekly. At terminal sacrifice, tumors were harvested, snap-frozen in liquid nitrogen, and stored at $-80^{\circ} \mathrm{C}$ until used for analysis of biomarkers associated with ILK inhibition. All experimental procedures using live animals were conducted in accordance with protocols approved by The Ohio State University Institutional Animal Care and Use Committee.

\section{Statistical analysis}

Quantitative data from in vitro experiments are presented as mean \pm SD. Data from in vivo experiments are expressed as mean \pm SEM. Differences among group means were analyzed for statistical significance using one-way ANOVA or unpaired Student's t-test. Differences were considered significant at $P<0.05$. All statistical analyses were performed using SPSS 
software (SPSS Inc., Chicago, IL, USA). Western blot and RT-PCR analyses were performed in triplicate.

\section{Acknowledgments}

This work is supported by National Institutes of Health Grant CA112250, and the Stephanie Spielman Fund for Breast Cancer Research. The authors thank Trent Godard for technical assistance in the synthesis of 22.

\section{Abbreviations}

$\begin{array}{ll}\text { ILK } & \text { integrin-linked kinase } \\ \text { PI3K } & \text { phosphatidylinositol-3-kinase } \\ \text { PIP3 } & \text { phosphatidylinositol 3,4,5-trisphosphate } \\ \text { PDK } & \text { phosphoinositide-dependent kinase } \\ \text { mTOR } & \text { mammalian target of rapamycin } \\ \text { mTORC2 } & \text { the rictor-mTOR complex } \\ \text { GSK3ß } & \text { glycogen synthase kinase 3 } \beta \\ \text { MLC } & \text { myosin light chain } \\ \text { SGK-1 } & \text { serum- and glucocorticoid-induced protein kinase 1 } \\ \text { PKCa } & \text { protein kinase C } \alpha \\ \text { MBP } & \text { myelin basic protein } \\ \text { CA } & \text { constitutively active } \\ \text { FAK } & \text { focal adhesion kinase }\end{array}$

\section{References}

1. Mora A, Komander D, van Aalten DM, Alessi DR. PDK1, the master regulator of AGC kinase signal transduction. Semin Cell Dev Biol. 2004; 15:161-170. [PubMed: 15209375]

2. Dong LQ, Liu F. PDK2: the missing piece in the receptor tyrosine kinase signaling pathway puzzle. Am J Physiol Endocrinol Metab. 2005; 289:E187-196. [PubMed: 16014356]

3. Hresko RC, Mueckler M. mTOR. RICTOR is the Ser473 kinase for Akt/protein kinase B in 3T3-L1 adipocytes. J Biol Chem. 2005; 280:40406-40416. [PubMed: 16221682]

4. Sarbassov DD, Guertin DA, Ali SM, Sabatini DM. Phosphorylation and regulation of Akt/PKB by the rictor-mTOR complex. Science. 2005; 307:1098-1101. [PubMed: 15718470]

5. Delcommenne M, Tan C, Gray V, Rue L, Woodgett J, Dedhar S. Phosphoinositide-3-OH kinasedependent regulation of glycogen synthase kinase 3 and protein kinase B/AKT by the integrinlinked kinase. Proc Natl Acad Sci U S A. 1998; 95:11211-11216. [PubMed: 9736715]

6. Persad S, Attwell S, Gray V, Delcommenne M, Troussard A, Sanghera J, Dedhar S. Inhibition of integrin-linked kinase (ILK) suppresses activation of protein kinase B/Akt and induces cell cycle arrest and apoptosis of PTEN-mutant prostate cancer cells. Proc Natl Acad Sci U S A. 2000; 97:3207-3212. [PubMed: 10716737]

7. Persad S, Attwell S, Gray V, Mawji N, Deng JT, Leung D, Yan J, Sanghera J, Walsh MP, Dedhar S. Regulation of protein kinase B/Akt-serine 473 phosphorylation by integrin-linked kinase: critical roles for kinase activity and amino acids arginine 211 and serine 343. J Biol Chem. 2001; 276:27462-27469. [PubMed: 11313365]

8. Hannigan GE, Leung-Hagesteijn C, Fitz-Gibbon L, Coppolino MG, Radeva G, Filmus J, Bell JC, Dedhar S. Regulation of cell adhesion and anchorage-dependent growth by a new beta 1-integrinlinked protein kinase. Nature. 1996; 379:91-96. [PubMed: 8538749] 
9. Hannigan G, Troussard AA, Dedhar S. Integrin-linked kinase: a cancer therapeutic target unique among its ILK. Nat Rev Cancer. 2005; 5:51-63. [PubMed: 15630415]

10. Legate KR, Montanez E, Kudlacek O, Fassler R. ILK, PINCH and parvin: the tIPP of integrin signalling. Nat Rev Mol Cell Biol. 2006; 7:20-31. [PubMed: 16493410]

11. Fielding AB, Dobreva I, McDonald PC, Foster LJ, Dedhar S. Integrin-linked kinase localizes to the centrosome and regulates mitotic spindle organization. J Cell Biol. 2008; 180:681-689. [PubMed: 18283114]

12. Wickstrom SA, Lange A, Montanez E, Fassler R. The ILK/PINCH/parvin complex: the kinase is dead, long live the pseudokinase! EMBO J. 2010; 29:281-291. [PubMed: 20033063]

13. Troussard AA, Mawji NM, Ong C, Mui A, St-Arnaud R, Dedhar S. Conditional knock-out of integrin-linked kinase demonstrates an essential role in protein kinase B/Akt activation. J Biol Chem. 2003; 278:22374-22378. [PubMed: 12686550]

14. Deng JT, Sutherland C, Brautigan DL, Eto M, Walsh MP. Phosphorylation of the myosin phosphatase inhibitors, CPI-17 and PHI-1, by integrin-linked kinase. Biochem J. 2002; 367:517524. [PubMed: 12144526]

15. Deng JT, Van Lierop JE, Sutherland C, Walsh MP. Ca2+-independent smooth muscle contraction. a novel function for integrin-linked kinase. J Biol Chem. 2001; 276:16365-16373. [PubMed: $11278951]$

16. Graff JR, Deddens JA, Konicek BW, Colligan BM, Hurst BM, Carter HW, Carter JH. Integrinlinked kinase expression increases with prostate tumor grade. Clin Cancer Res. 2001; 7:19871991. [PubMed: 11448915]

17. Ahmed N, Riley C, Oliva K, Stutt E, Rice GE, Quinn MA. Integrin-linked kinase expression increases with ovarian tumour grade and is sustained by peritoneal tumour fluid. J Pathol. 2003; 201:229-237. [PubMed: 14517840]

18. Pontier SM, Huck L, White DE, Rayment J, Sanguin-Gendreau V, Hennessy B, Zuo D, St-Arnaud R, Mills GB, Dedhar S, Marshall CJ, Muller WJ. Integrin-linked kinase has a critical role in ErbB2 mammary tumor progression: implications for human breast cancer. Oncogene. 2010; 29:33743385. [PubMed: 20305688]

19. Bravou V, Klironomos G, Papadaki E, Taraviras S, Varakis J. ILK over-expression in human colon cancer progression correlates with activation of beta-catenin, down-regulation of E-cadherin and activation of the Akt-FKHR pathway. J Pathol. 2006; 208:91-99. [PubMed: 16278819]

20. Schaeffer DF, Assi K, Chan K, Buczkowski AK, Chung SW, Scudamore CH, Weiss A, Salh B, Owen DA. Tumor expression of integrin-linked kinase (ILK) correlates with the expression of the E-cadherin repressor snail: an immunohistochemical study in ductal pancreatic adenocarcinoma. Virchows Arch. 2010; 456:261-268. [PubMed: 20091050]

21. Ito R, Oue N, Zhu X, Yoshida K, Nakayama H, Yokozaki H, Yasui W. Expression of integrinlinked kinase is closely correlated with invasion and metastasis of gastric carcinoma. Virchows Arch. 2003; 442:118-123. [PubMed: 12596061]

22. Chan J, Ko FC, Yeung YS, Ng IO, Yam JW. Integrin-linked kinase overexpression and its oncogenic role in promoting tumorigenicity of hepatocellular carcinoma. PLoS One. 2011; 6:e16984. [PubMed: 21347395]

23. Zhu J, Song X, Lin HP, Young DC, Yan S, Marquez VE, Chen CS. Using cyclooxygenase-2 inhibitors as molecular platforms to develop a new class of apoptosis-inducing agents. J Natl Cancer Inst. 2002; 94:1745-1757. [PubMed: 12464646]

24. Zhu J, Huang JW, Tseng PH, Yang YT, Fowble J, Shiau CW, Shaw YJ, Kulp SK, Chen CS. From the cyclooxygenase-2 inhibitor celecoxib to a novel class of 3-phosphoinositide-dependent protein kinase-1 inhibitors. Cancer Res. 2004; 64:4309-4318. [PubMed: 15205346]

25. Garcia-Martinez JM, Alessi DR. mTOR complex 2 (mTORC2) controls hydrophobic motif phosphorylation and activation of serum- and glucocorticoid-induced protein kinase 1 (SGK1). Biochem J. 2008; 416:375-385. [PubMed: 18925875]

26. Ikenoue T, Inoki K, Yang Q, Zhou X, Guan KL. Essential function of TORC2 in PKC and Akt turn motif phosphorylation, maturation and signalling. EMBO J. 2008; 27:1919-1931. [PubMed: 18566587] 
27. Kalra J, Sutherland BW, Stratford AL, Dragowska W, Gelmon KA, Dedhar S, Dunn SE, Bally MB. Suppression of Her2/neu expression through ILK inhibition is regulated by a pathway involving TWIST and YB-1. Oncogene. 2010; 29:6343-6356. [PubMed: 20838384]

28. Stratford AL, Habibi G, Astanehe A, Jiang H, Hu K, Park E, Shadeo A, Buys TP, Lam W, Pugh T, Marra M, Nielsen TO, Klinge U, Mertens PR, Aparicio S, Dunn SE. Epidermal growth factor receptor (EGFR) is transcriptionally induced by the Y-box binding protein-1 (YB-1) and can be inhibited with Iressa in basal-like breast cancer, providing a potential target for therapy. Breast Cancer Res. 2007; 9:R61. [PubMed: 17875215]

29. Eke I, Leonhardt F, Storch K, Hehlgans S, Cordes N. The small molecule inhibitor QLT0267 Radiosensitizes squamous cell carcinoma cells of the head and neck. PLoS One. 2009; 4:e6434. [PubMed: 19649326]

30. Cary LA, Guan JL. Focal adhesion kinase in integrin-mediated signaling. Front Biosci. 1999; 4:D102-113. [PubMed: 9889179]

31. Huang Y, Li J, Zhang Y, Wu C. The roles of integrin-linked kinase in the regulation of myogenic differentiation. J Cell Biol. 2000; 150:861-872. [PubMed: 10953009]

32. Su JL, Chiou J, Tang CH, Zhao M, Tsai CH, Chen PS, Chang YW, Chien MH, Peng CY, Hsiao M, Kuo ML, Yen ML. CYR61 regulates BMP-2-dependent osteoblast differentiation through the $\{$ alpha $\}$ ₹ beta 3 integrin/integrin-linked kinase/ERK pathway. J Biol Chem. 2010; 285:3132531336. [PubMed: 20675382]

33. White DE, Cardiff RD, Dedhar S, Muller WJ. Mammary epithelial-specific expression of the integrin-linked kinase (ILK) results in the induction of mammary gland hyperplasias and tumors in transgenic mice. Oncogene. 2001; 20:7064-7072. [PubMed: 11704830]

34. Tabe Y, Jin L, Tsutsumi-Ishii Y, Xu Y, McQueen T, Priebe W, Mills GB, Ohsaka A, Nagaoka I, Andreeff M, Konopleva M. Activation of integrin-linked kinase is a critical prosurvival pathway induced in leukemic cells by bone marrow-derived stromal cells. Cancer Res. 2007; 67:684-694. [PubMed: 17234779]

35. Esfandiarei M, Yazdi SA, Gray V, Dedhar S, van Breemen C. Integrin-linked kinase functions as a downstream signal of platelet-derived growth factor to regulate actin polymerization and vascular smooth muscle cell migration. BMC Cell Biol. 2010; 11:16. [PubMed: 20178627]

36. Ishii T, Satoh E, Nishimura M. Integrin-linked kinase controls neurite outgrowth in N1E-115 neuroblastoma cells. J Biol Chem. 2001; 276:42994-43003. [PubMed: 11560928]

37. Leung-Hagesteijn C, Hu MC, Mahendra AS, Hartwig S, Klamut HJ, Rosenblum ND, Hannigan GE. Integrin-linked kinase mediates bone morphogenetic protein 7-dependent renal epithelial cell morphogenesis. Mol Cell Biol. 2005; 25:3648-3657. [PubMed: 15831470]

38. Sawai H, Okada Y, Funahashi H, Matsuo Y, Takahashi H, Takeyama H, Manabe T. Integrinlinked kinase activity is associated with interleukin-1 alpha-induced progressive behavior of pancreatic cancer and poor patient survival. Oncogene. 2006; 25:3237-3246. [PubMed: 16407822]

39. Codogno P, Meijer AJ. Autophagy and signaling: their role in cell survival and cell death. Cell Death Differ. 2005; 12 (Suppl 2):1509-1518. [PubMed: 16247498]

40. Troussard AA, McDonald PC, Wederell ED, Mawji NM, Filipenko NR, Gelmon KA, Kucab JE, Dunn SE, Emerman JT, Bally MB, Dedhar S. Preferential dependence of breast cancer cells versus normal cells on integrin-linked kinase for protein kinase B/Akt activation and cell survival. Cancer Res. 2006; 66:393-403. [PubMed: 16397254]

41. Kalra J, Warburton C, Fang K, Edwards L, Daynard T, Waterhouse D, Dragowska W, Sutherland BW, Dedhar S, Gelmon K, Bally M. QLT0267, a small molecule inhibitor targeting integrinlinked kinase (ILK), and docetaxel can combine to produce synergistic interactions linked to enhanced cytotoxicity, reductions in P-AKT levels, altered F-actin architecture and improved treatment outcomes in an orthotopic breast cancer model. Breast Cancer Res. 2009; 11:R25. [PubMed: 19409087]

42. Matsumoto K, Bay BH. Significance of the Y-box proteins in human cancers. J Mol Genet Med. 2005; 1:11-17. [PubMed: 19565008] 


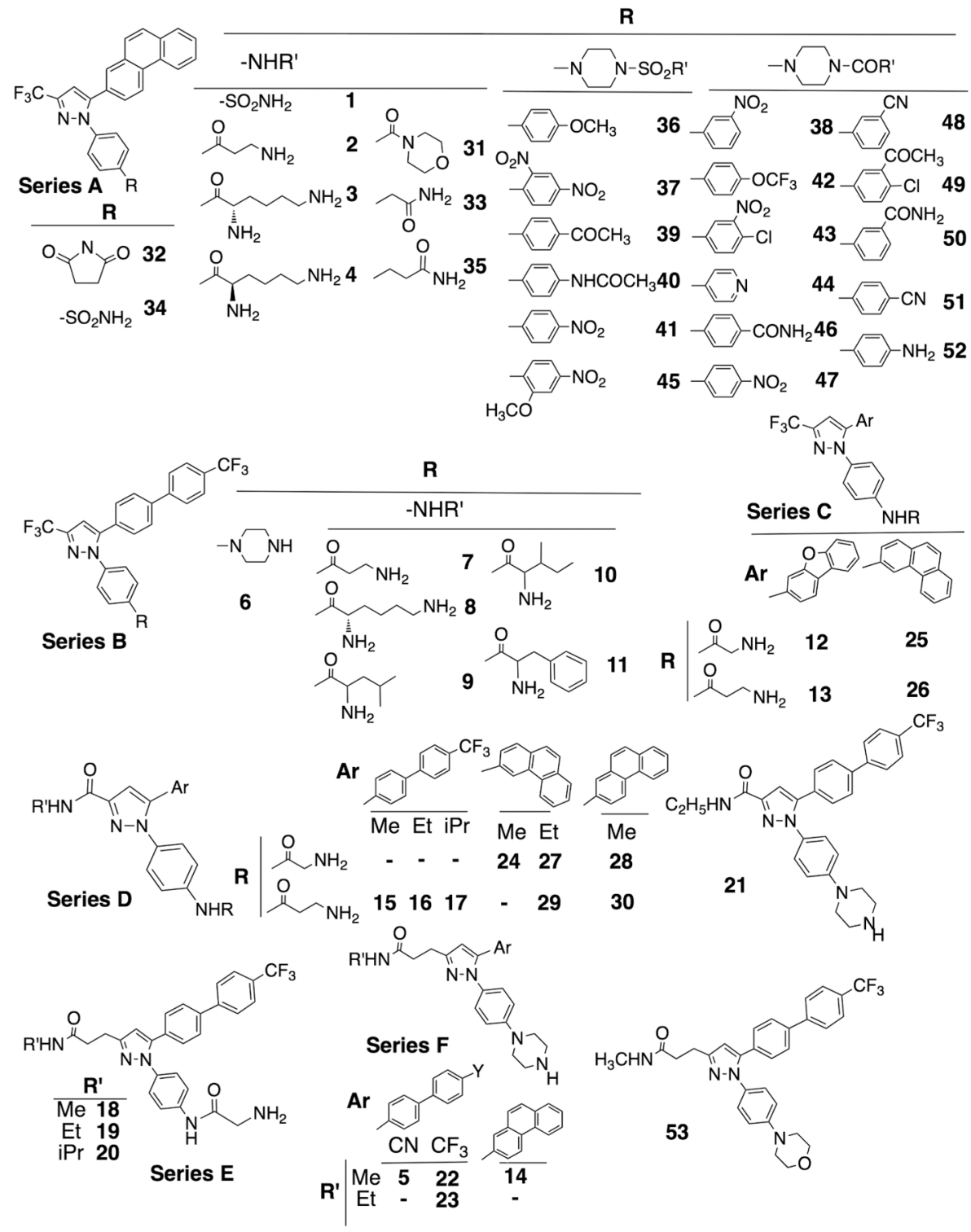

Figure 1.

Chemical structures of 1-53 in the focused compound library used for the biomolecular screening of ILK inhibitors. 


\section{A}

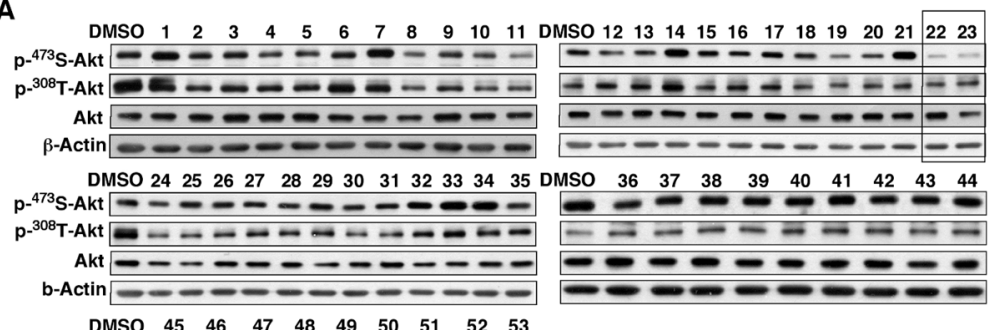

$\begin{array}{rrrrrrrrrrr}\text { DMSO } & 45 & 46 & 47 & 48 & 49 & 50 & 51 & 52 & 53\end{array}$

p-308T-Akt $=--\infty-\cdots-\cdots$

Akt $-2-1-2-1$

B-Actin $-\infty-\infty-\infty-\infty-\infty$

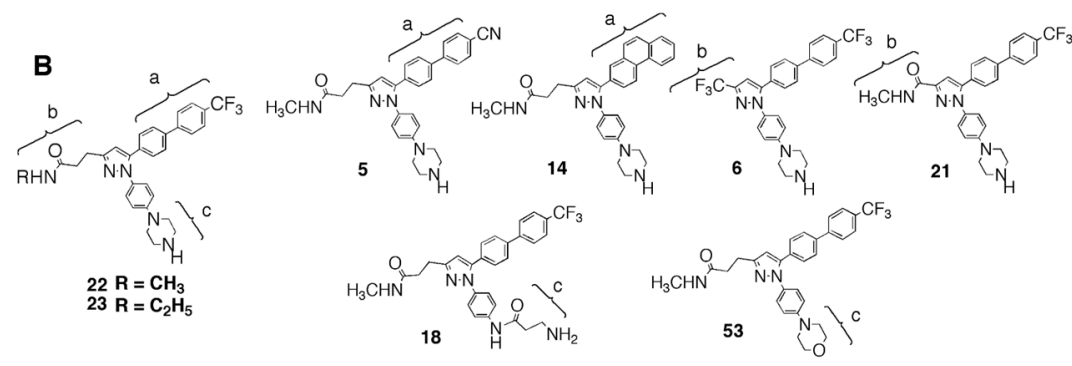

Figure 2.

(A) Identification of putative PDK2 inhibitors by screening of an in-house focused compound library. Western blot analysis of the effects of $\mathbf{1}-\mathbf{5 3}$ versus DMSO control on the phosphorylation of Akt on Ser-473 versus Thr-308 in PC-3 cells. Cells were exposed to individual test agents at $2.5 \mu \mathrm{M}$ or DMSO vehicle in 5\% FBS-supplemented RPMI 1640 medium for $24 \mathrm{~h}$. (B) SAR analysis of $\mathbf{2 2 / 2 3}$ versus the structurally related but PDK2inactive derivatives, $\mathbf{5}, \mathbf{1 4}, \mathbf{6}, \mathbf{2 1}, \mathbf{1 8}$, and $\mathbf{5 3}$. As shown, modifications in any of the three peripheral structural motifs, designated as a - c, of 22 led to loss of the Akt Ser-473 dephosphorylating activity, indicating a stringent structural requirement. 
A

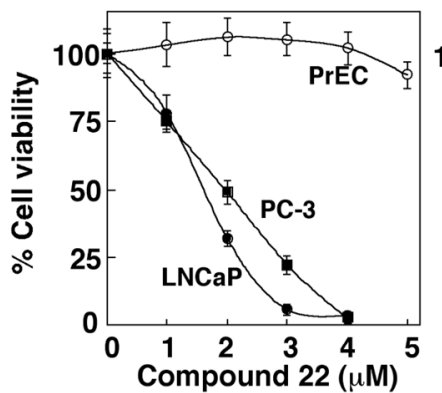

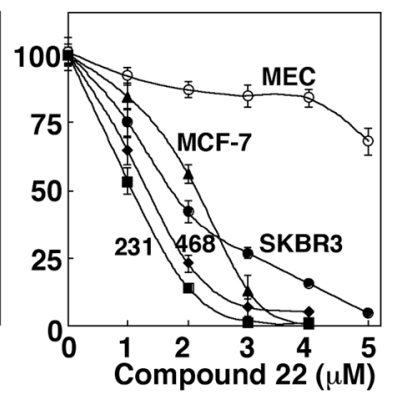

B ShRNA; PC-3

Compound $22(\mu \mathrm{M})$

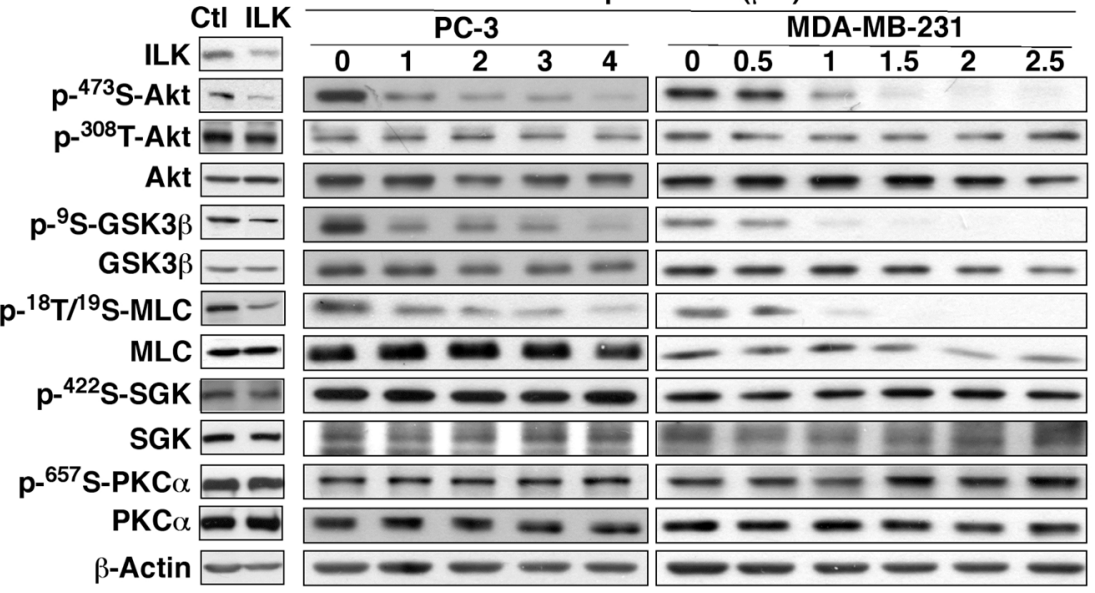

Figure 3.

Effects of 22 on cell viability and ILK signaling. (A) Dose-dependent suppressive effects of 22 on the viability of PC-3 and LNCaP prostate cancer cells versus PrECs (left panel), and of MDA-MB-231, MDA-MB-468, SKBR3, and MCF-7 breast cancer cells versus MECs (right panel) in 5\% FBS-supplemented medium after $24 \mathrm{~h}$ of treatment. Cell viability was determined by MTT assays. Points, means; bars, SD $(\mathrm{n}=6)$. (B) Western blot analysis of the suppressive effects of shRNA-mediated knockdown of ILK and 22 on the phosphorylation of Akt at Ser-473 and Thr-308 and the downstream targets of ILK (GSK3 $\beta$ and MLC) versus those of mTORC2 (SGK and PKC $\alpha$ ) in PC-3 and/or MDA-MB-231 cells. Cells were exposed to 22 at the indicated concentrations for $24 \mathrm{~h}$ in 5\% FBS-supplemented medium. The immunoblots shown are representative of three independent experiments. 

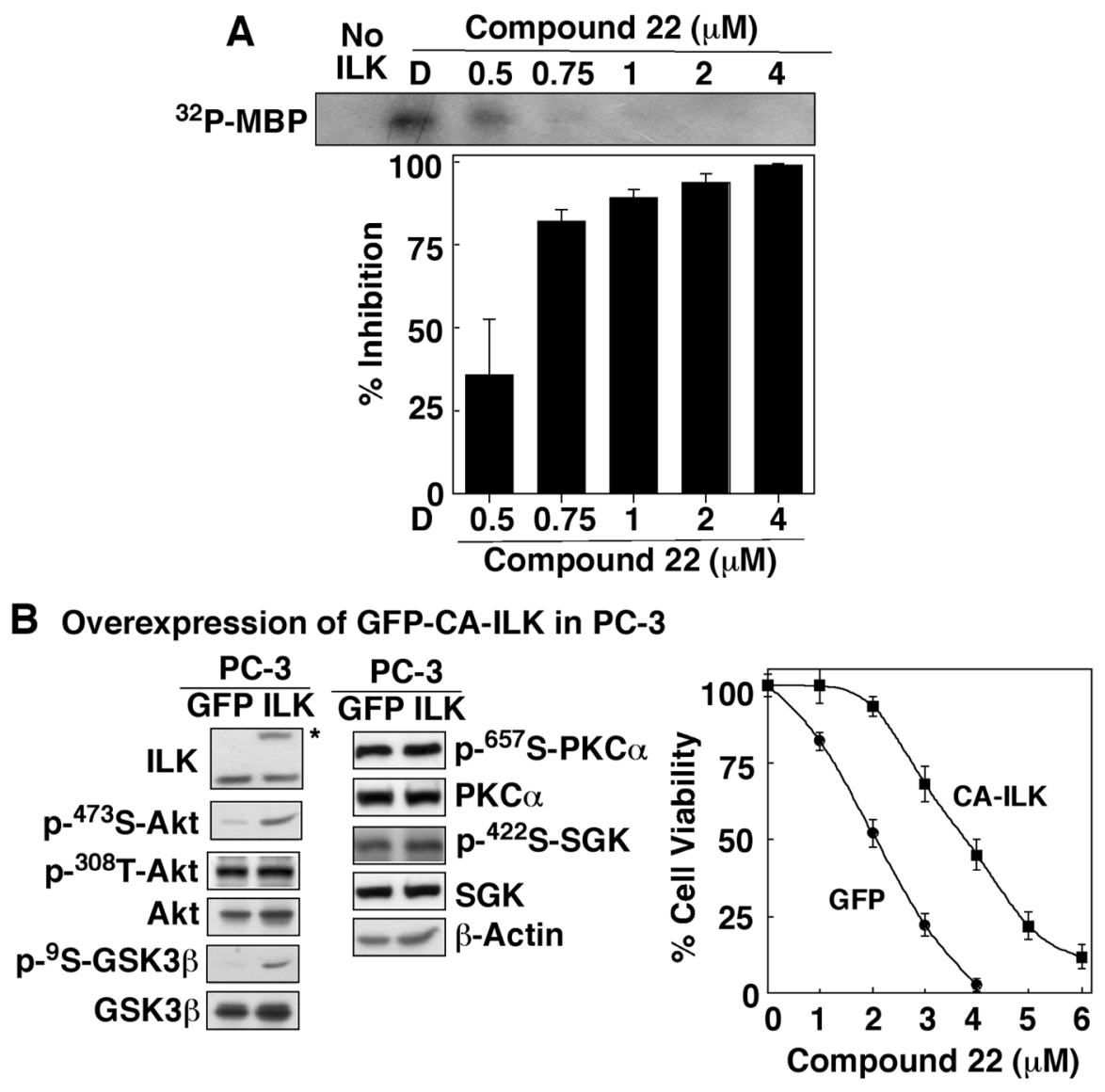

Figure 4.

Evidence that $\mathbf{2 2}$ is an ILK inhibitor. (A) Dose-dependent suppressive effect of $\mathbf{2 2}$ on the kinase activity of immunoprecipitated ILK. Kinase activity was determined in the presence of 22 at the indicated concentrations by measuring ${ }^{32} \mathrm{P}$-phosphorylation of the ILK substrate MBP as described in the Experimental Section. Data are presented as means \pm SD $(n=3)$. (B) Effects of ectopic expression of GFP-tagged CA-ILK versus GFP alone on the phosphorylation of Akt, GSK3 $\beta$, PKC $\alpha$, and SGK in stable PC-3 transfectants (left panel) and on the viability of PC-3 cells after 24 h-treatment with 22 at different concentrations in $5 \%$ FBS-supplemented medium (right panel). Blot on the left confirms the presence of the CA-ILK protein (*) in transfected PC-3 cells. The immunoblots shown are representative of three independent experiments. Points, means; bars, SD $(\mathrm{n}=6)$. 


\section{A}

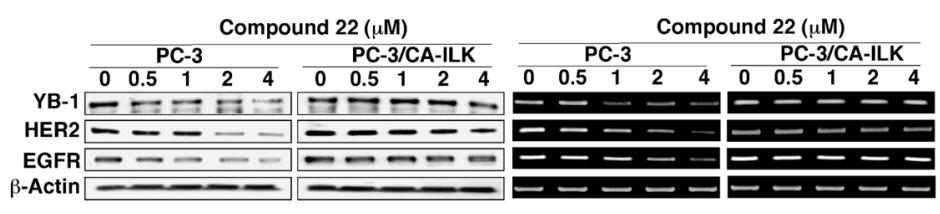

B

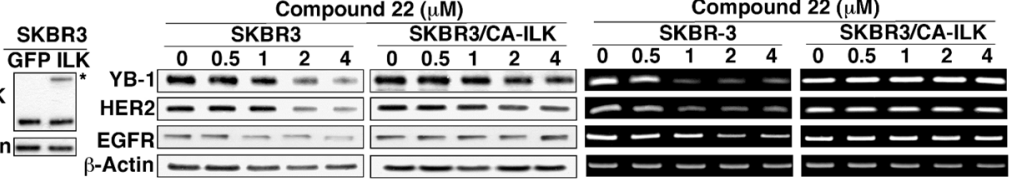

Figure 5.

Dose-dependent effects of $\mathbf{2 2}$ on the protein (left panel) and mRNA (right panel) expression of YB-1 and its targets HER2 and EGFR in (A) PC-3 cells versus stable PC-3 transfectants expressing CA-ILK (PC-3/CA-ILK), and (B) SKBR3 cells versus transient SKBR3 transfectants expressing ectopic CA/ILK (SKBR3/CA-ILK). Cells were treated with 22 at the indicated concentrations in 5\% FBS-supplemented medium for $24 \mathrm{~h}$. These data are representative of three independent experiments. Blot on the left confirms the presence of the CA-ILK protein $\left(^{*}\right)$ in transfected SKBR3 cells. 
A

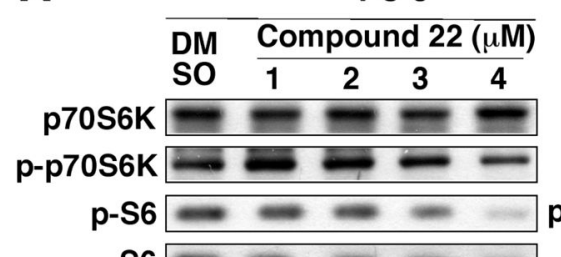

S6

p-Y ${ }^{397}$ FAK

FAK

p-ERK $1 / 2$

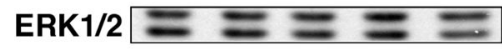

p-p38

p38

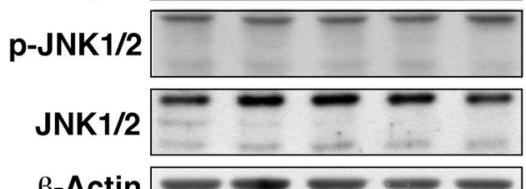

$\beta$-Actin $=2$
B

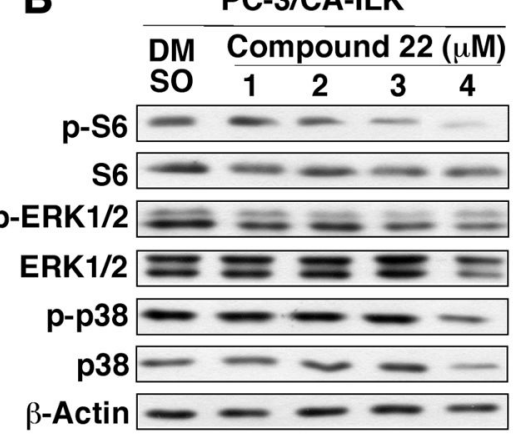

Figure 6.

Specificity of 22 in kinase inhibition. (A) Western blot analysis of the dose-dependent effect of 22 on the phosphorylation of p70S6K, S6, Tyr-397-FAK, ERKs, p38, and JNK in PC-3 cells. Cells were exposed to the indicated concentrations of 22 in 5\% FBS-supplemented medium for $24 \mathrm{~h}$. (B) Effects of the stable expression of CA-ILK, as depicted in Fig. 4B, on 22-mediated dephosphorylation of S6, ERKs, and p38 in PC-3 cells. The immunoblots shown are representative of three independent experiments. 


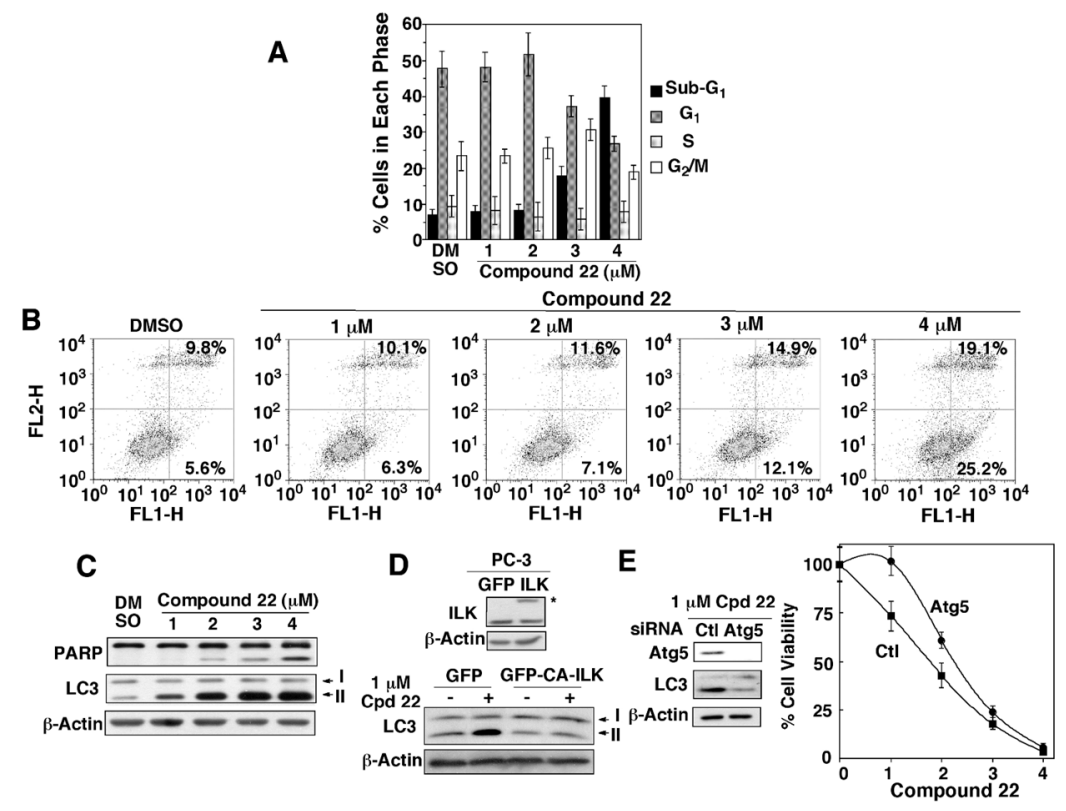

Figure 7.

Evidence that 22 induces cell death through both apoptosis and autophagy. (A) Histograms depicting the percentages of PC-3 cells at various phases of the cell cycle after exposure to the indicated concentrations 22 in 5\% FBS-supplemented medium for $24 \mathrm{~h}$. Each data point represents the mean $\pm \mathrm{SD}(\mathrm{n}=3)$. (B) Dose-dependent effect of $\mathbf{2 2}$ on the extent of apoptosis induction, as detected by annexin V/PI staining. The values in the right upper and lower quadrants denote the average of three independent experiments. (C) Dose-dependent effects of 22 on PARP cleavage and LC3-II conversion in PC-3 cells after 24 h of treatment. (D) Protective effect of the stable transfection of CA-ILK (*), as depicted in Fig. 4B, on the induction of LC3-II conversion by $1 \mu \mathrm{M} 22$ in PC-3 cells. (E) siRNA-mediated knockdown of Atg5 inhibited 22-induced autophagy (left panel) as determined by LC3-II conversion, and provided partial protection against 22-mediated suppression of PC-3 cell viability (right panel). Points, means; bars, SD $(\mathrm{n}=6)$. All immunoblots shown are representative of three independent experiments. 


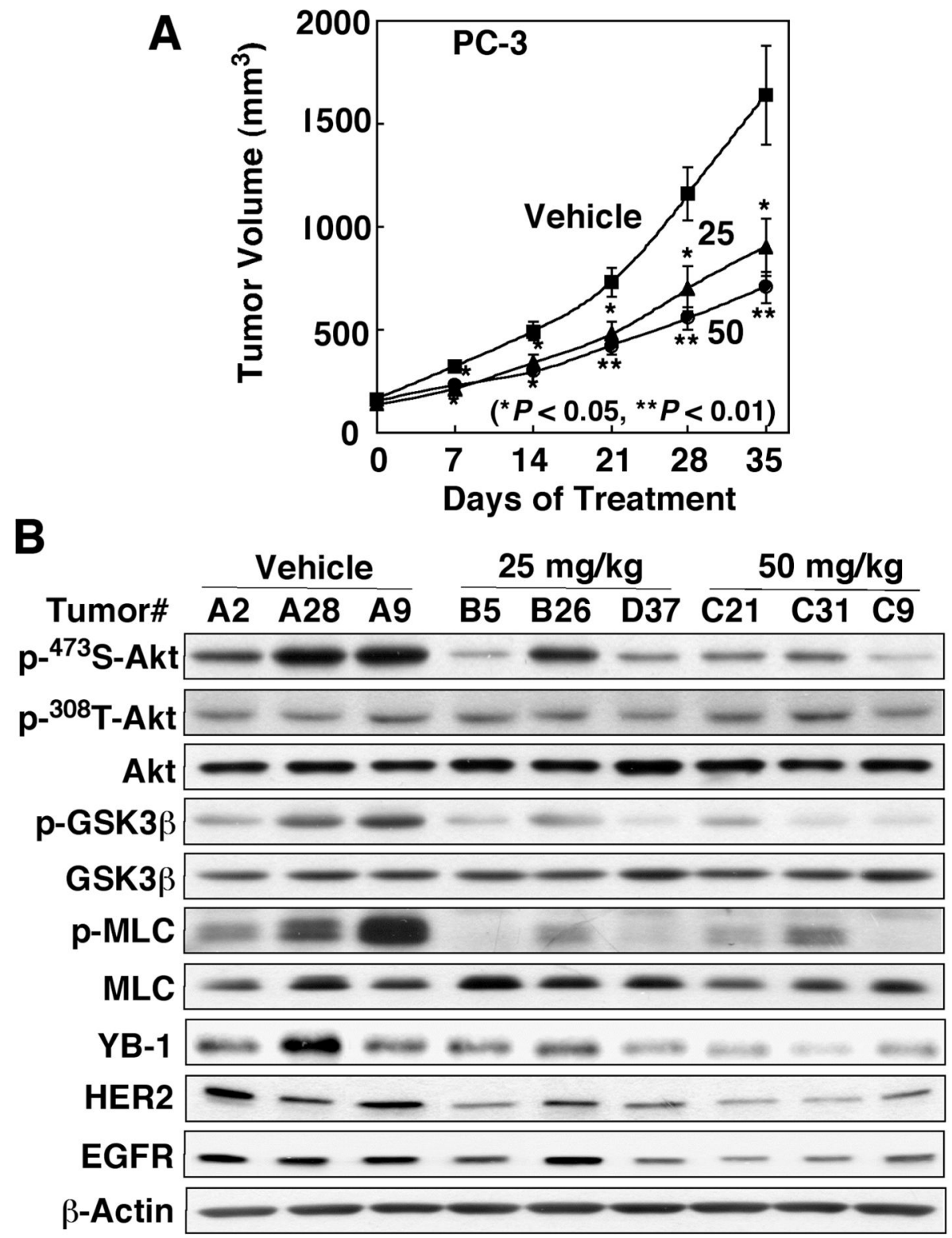

B

Figure 8.

In vivoantitumor efficacy of 22. (A) Effect of oral 22 on PC-3 xenograft tumor growth in athymic nude mice. Mice with established s.c. PC-3 xenograft tumors were treated orally once daily with 22 at 25 and $50 \mathrm{mg} / \mathrm{kg}$ or vehicle for 35 days and tumor growth was monitored as described in the Experimental Section. Points, mean; bars, SEM $(\mathrm{n}=6)$. (B) Western blot analysis of intratumoral biomarkers of drug activity in three representative PC-3 tumors from each group of mice treated for 35 days as described above in (A). 


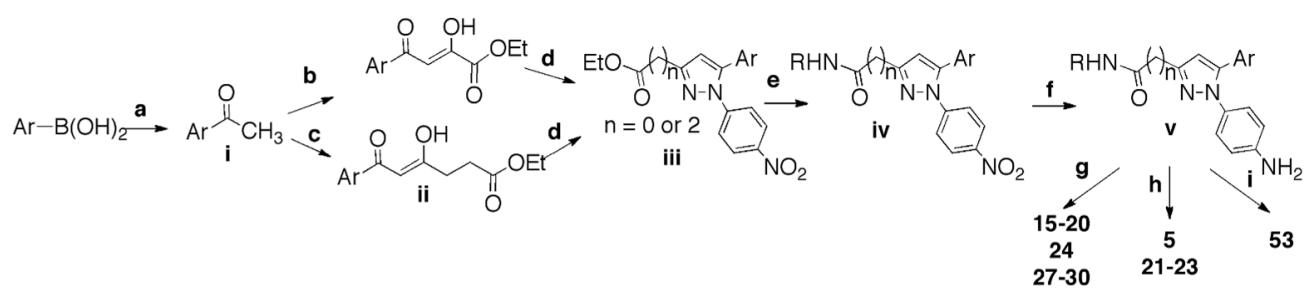

Scheme 1.

General synthetic procedures for $\mathbf{5}, \mathbf{1 5 - 2 4}, \mathbf{2 7 - 3 0}$, and 53. Reaction conditions: a, 1-(4bromophenyl)ethanone, $\mathrm{Bu}_{4} \mathrm{NBr}, \mathrm{K}_{2} \mathrm{CO}_{3}, \mathrm{Pd}(\mathrm{OAc})_{2}$ (cat.), $\mathrm{H}_{2} \mathrm{O}, 60^{\circ} \mathrm{C}$; b, diethyl oxalate, $\mathrm{NaH}$, THF; c, ethyl 4-(1H-benzo[d][1,2,3]triazol-1-yl)-4-oxobutanoate, $\mathrm{MgBr}_{2}, \mathrm{CH}_{2} \mathrm{Cl}_{2}$, DIPEA; (d) (4-nitrophenyl)hydrazine hydrochloride, TsOH, EtOH, microwave $130{ }^{\circ} \mathrm{C}, 10$ min; e, $\mathrm{NH}_{2} \mathrm{R}\left(\mathrm{R}=\mathrm{CH}_{3}\right.$ or $\left.\mathrm{C}_{2} \mathrm{H}_{5}\right)$ in $\mathrm{EtOH}, 120^{\circ} \mathrm{C} ; \mathrm{f}, \mathrm{H}_{2}$ (g) $70 \mathrm{psi}, 10 \% \mathrm{Pd} / \mathrm{C}, \mathrm{MeOH} /$ EtOAc; g, bis(2-chloroethyl)amine hydrochloride, xylene, $170{ }^{\circ} \mathrm{C} ; \mathrm{h}, \mathrm{CH}_{3} \mathrm{I}, \mathrm{K}_{2} \mathrm{CO}_{3}, \mathrm{AcCN}$, $50{ }^{\circ} \mathrm{C} ;$ i, 1-iodo-2-(2-iodoethoxy)ethane, xylene, $170{ }^{\circ} \mathrm{C}$. 